\title{
Synthesis and biological evaluation of new 2-(4-fluorophenyl) imidazol-5-ones as anticancer agents
}

\author{
Yasmin A. Abo-Elanwar ${ }^{1}$, Amany S. Mostafa ${ }^{1 *}$, Magda A. A. El-Sayed ${ }^{1,2}$, Magda N. A. Nasr ${ }^{1}$ \\ ${ }^{1}$ Department of Pharmaceutical Organic Chemistry, Faculty of Pharmacy, Mansoura University, Mansoura, Egypt. \\ ${ }^{2}$ Department of Pharmaceutical Chemistry, Faculty of Pharmacy, Horus University, New Damietta, Egypt.
}

\section{ARTICLE INFO \\ Received on: 16/12/2018 \\ Accepted on: 08/03/2019 \\ Available online: 08/05/2019}

Key words:

Imidazlone, chalcones, anticancer, VEGFR-2,

CDK2A.

\begin{abstract}
Two series of imidazolones were designed, synthesized, and evaluated for their anticancer activity against four cancer cell lines: Hela, MCF-7, PC3, and HCT-116, where four compounds 6, 25, 26, and 29 showed good potency against the whole panel. Compound $\mathbf{3 0}$ showed a cytotoxic effect against PC3 cell lines compared to that of the standard doxorubicin with $\mathrm{IC}_{50}=8.15 \mu \mathrm{M}$, while compounds $\mathbf{4}$ and $\mathbf{1 8}$ showed moderate activity with $\mathrm{IC}_{50}$ range of 10.58-11.45 $\mu \mathrm{M}$. Enzyme inhibition assay was implemented against CDK2A and VEGFR-2; where varied activities were obtained. Compound 6 exhibited the highest inhibitory activity against VEGFR-2 with an $\mathrm{IC}_{50}$ value of $67 \mathrm{nM}$ and moderate inhibition against CDK2A, while compound 26 achieved the best result against CDK2A with an $\mathrm{IC}_{50}$ value of $0.66 \mu \mathrm{M}$.
\end{abstract}

\section{INTRODUCTION}

Cancer development process basically results from the uncontrolled growth of mutated or abnormal body cells, whereas normal cells are under strict control of various growth pattern checkpoints, the neoplastic cells typically do not obey these rules and are continuously and uncontrollably proliferating. Normally, during the process of mitosis, any abnormalities during cell division are controlled by a set of physiological processes "apoptosis" ending up in damaged cell death (Spano et al., 2016). Nevertheless, if the cells are mutated and not controlled by the programmed cell death and/or acquire the ability to escape several checkpoints, they turn to be malignant cells that are able to invade and metastasize (Kalyanaraman, 2017).

Various compounds have been studied as anticancer agents throughout the work on the different phases of the cell cycle. These compounds include at most the $N$-containing heterocycles (Akhtar et al., 2017), among which imidazole ring

"Corresponding Author

Amany S. Mostafa, Department of Pharmaceutical Organic Chemistry, Faculty of Pharmacy, Mansoura University, Mansoura, Egypt. Email: amanysalah2002@yahoo.com system represents the main core structure. Imidazole and its derivatives have a great prevalence in both natural products and synthetic molecules. Having the unique structural features with the desirable electron-rich characteristic enables these compounds to readily bind with different enzymes and receptors, thereby exhibiting broad bioactivities (Zhang et al., 2014). Various activities including anticancer, anti-inflammatory (Rapolu et al., 2013), antimicrobial (Premakumari et al., 2014), cardio-activity, and angiotensin-II receptor antagonistic activity have been depicted specifically in compounds containing imidazolone moiety (Padmaja et al., 2011). Furthermore, many imidazolones have been used as biotin antagonists capable of inhibiting the growth of malignant tumors like compound I (AK et al., 2017). For instance, the cytotoxic activity of imidazolone derivatives I and II against cervical cancer (HeLa), breast cancer (MCF-7), leukemia cells (HL-60), and hepatocellular carcinoma (HepG2) cell lines were characterized in vitro (AK et al., 2017; Kumar et al., 2017). Besides, the 2-aminoimidazolone III showed great potency toward HCT116 and $\mathrm{H} 460$ cell lines $\left(\mathrm{IC}_{50}\right.$ of 1 and $2 \mu \mathrm{M}$, respectively) (Dražić et al., 2015) (Fig. 1).

Imidazolones linked to chalcone moiety were shown to have excellent antioxidant and anticancer activities on various cell lines (Mahapatra et al., 2015; Mai et al., 2014; Ramaiah et al., 2011), like compound IV (Kamal et al., 2010) that possess great 


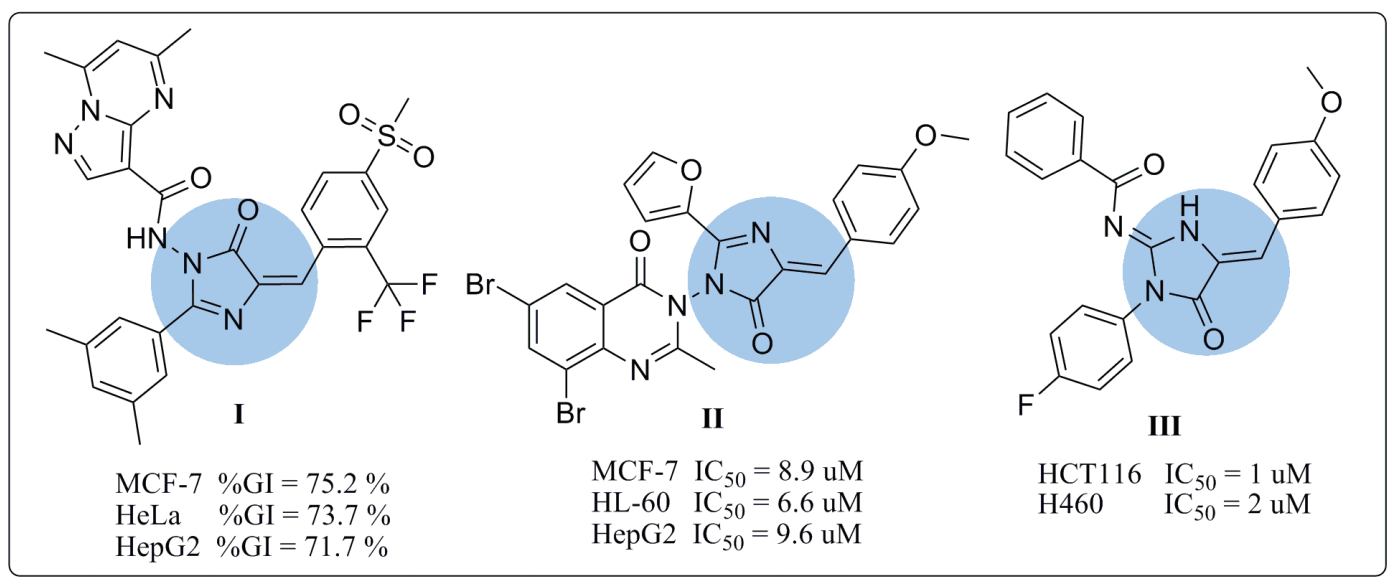

Figure 1. Reported antitumor agents with imidazolone nucleus.

potency against HCT116 and MCF-7 cell lines with $\mathrm{GI}_{50}$ values of 1.40 and $1.55 \mu \mathrm{M}$, respectively. It has been proved that imidazolone hybridized with chalcone moiety displayed potential antineoplastic activity through different biological mechanisms (Nasir Abbas Bukhari et al., 2013). Certain derivatives cause distinctive DNA damage specifically at telomeres and subsequently cause apoptosis (Ramaiah et al., 2011). Further mechanisms included assorted protein kinase inhibition (CDK, PLK1, MK-2, and Eg5), Topo (I, II), as well as microtubular inhibition (Akhtar et al., 2017). Moreover, they show p21 up-regulation and control damage pathway of DNA (Ramaiah et al., 2011; Yin et al., 2016).

Based on the preceded data, we aim at functionalizing imidazolone-based scaffold in the design and synthesis of novel derivatives to be evaluated as anticancer agents, and exploring the plausible mechanisms by which they could exert such activity. In the current study, compound $\mathbf{I V}$ was chosen as the lead compound to design the new imidazolone derivatives. Rational design depended on the maintenance of the basic structural features characterizing the lead compound, mainly the imidazolone core, by replacing the 2-imidazolone ring by 4-substituted-5-imidazolone in all the designed series. Besides, optimizing the whole scaffold throughout either substitution of certain groups or replacement with various moieties, including either five or six-membered heterocyclic moieties, was accomplished to investigate the potential effect on anti-tumoral activity (Fig. 2).

\section{MATERIALS AND METHODS}

Melting points $\left({ }^{\circ} \mathrm{C}\right)$ were measured with Fisher-Johns melting point apparatus and are uncorrected. Microanalyses $(C$, $\mathrm{H}$, and $\mathrm{N}$ ) were performed in the Microanalytical unit, Cairo University, and all the results were within \pm 0.5 . IR spectra were recorded on Thermo Fisher Scientific Nicolet IS10 spectrometer $\left(v\right.$ in $\mathrm{cm}^{-1}$ ) using $\mathrm{KBr}$ disk at Faculty of Pharmacy, Mansoura University. Mass MS (EI) $m / z$ analyses were performed on Thermo Scientific DCQII at Faculty of Science, Mansoura University. ${ }^{1} \mathrm{H}$ and ${ }^{13} \mathrm{C}$-NMR spectra were achieved in dimethyl sulfoxide (DMSO)- $d_{6}$ on ASCEND spectrometer $(400 \mathrm{MHz})$ Bruker using TMS (chemical shifts in ppm, $\delta$ units) at Georgia State University USA, Kafrelsheikh University, and at Mansoura University. Reaction times were determined using TLC on Silica gel plates $60 \mathrm{~F}_{254}$ (E. Merk), and UV (366, $245 \mathrm{~nm}$ ) was used to visualize the spots.
2-(4-Fluorobenzoylamino) acetic acid (1) was prepared according to the reported procedure. Yield 75\% (reported 84\%) and $\mathrm{mp} 168^{\circ} \mathrm{C}-170^{\circ} \mathrm{C}$ (reported $167^{\circ} \mathrm{C}-169^{\circ} \mathrm{C}$ ) (El-Araby et al., 2012).

\section{General procedure for synthesis of compounds 2 and 3}

A mixture of compound 1 (1 mmol, $0.197 \mathrm{~g})$, the appropriate heterocyclic aldehyde $(1 \mathrm{mmol})$, and freshly-fused sodium acetate $(0.049 \mathrm{~g})$ in acetic anhydride $(1.97 \mathrm{ml})$ was refluxed overnight at $130^{\circ} \mathrm{C}$. The obtained crystals were filtered, washed with cold water, followed by aq. EtOH and recrystallized from EtOH.

2-(4-Fluorophenyl)-4-(furan-2-ylmethylene)oxazol-5(4H)-one (2)

Yield $68 \%$; mp $165^{\circ} \mathrm{C}-167^{\circ} \mathrm{C} ;{ }^{1} \mathrm{H}$ NMR (DMSO $d_{6}$ ): 6.87-7.02 ( $m, 3 H$, Ar-H), $7.44(s, 1 H$, olefinic-H), and 7.61-7.93 ( $m, 4 H, \mathrm{Ar}-\mathrm{H})$; MS (EI) m/z \%: $257\left(45.5, \mathrm{M}^{+}\right)$; IR cm $\mathrm{cm}^{-1}: 1,775$ $(\mathrm{C}=\mathrm{O}), 1,650(\mathrm{C}=\mathrm{N})$; Anal. calcd for $\mathrm{C}_{14} \mathrm{H}_{8} \mathrm{FNO}_{3}: \mathrm{C}, 65.37 ; \mathrm{H}$, 3.13; and N, 5.45. Found: C, 65.29; H, 3.02; and N, 5.32.

(E)-2-(4-Fluorophenyl)-4-(thiophen-2-ylmethylene)oxazol-5(4H)one (3)

Yield $70 \%$; mp $173^{\circ} \mathrm{C}-175^{\circ} \mathrm{C} ;{ }^{1} \mathrm{H}$ NMR (DMSO $d_{6}$ ): 7.16-7.28 ( $m, 3 H, \mathrm{Ar}-\mathrm{H}), 7.48(\mathrm{~s}, 1 \mathrm{H}$, olefinic-H), and 7.54-7.76 ( $m, 4 H, \mathrm{Ar}-\mathrm{H})$; MS (EI) m/z \%: $274\left(2.6, \mathrm{M}^{+}+1\right), 273\left(4.2, \mathrm{M}^{+}\right)$; IR $\mathrm{cm}^{-1}$ : 1,780 $(\mathrm{C}=\mathrm{O}), 1,656(\mathrm{C}=\mathrm{N})$; Anal. calcd for $\mathrm{C}_{14} \mathrm{H}_{8} \mathrm{FNO}_{2} \mathrm{~S}: \mathrm{C}$, 61.53; H, 2.95; and N, 5.13. Found: C, 61.11; H, 2.45; and N, 5.11.

\section{General procedure for synthesis of compounds 4-17}

A mixture of compound $\mathbf{2}$ or $\mathbf{3}$ (1 mmol), the appropriate aromatic amine $(1 \mathrm{mmol})$, and freshly-fused Na-acetate $(0.3 \mathrm{~g})$ in glacial acetic acid $(7 \mathrm{ml})$ was refluxed overnight in boiling water bath, maintaining continuous stirring. The product was filtered, then washed with aq. EtOH, and recrystallized from EtOH.

(E)-2-(4-Fluorophenyl)-4-(furan-2-ylmethylene)-1-phenyl-1Himidazol-5(4H)-one (4)

Yield $68 \%$; mp $148^{\circ} \mathrm{C}-150{ }^{\circ} \mathrm{C} ;{ }^{1} \mathrm{H}$ NMR (DMSO $d_{6}$ ): $6.85(\mathrm{~s}, 1 \mathrm{H}$, olefinic-H), 7.15-7.25 ( $\mathrm{m}, 3 \mathrm{H}, \mathrm{Ar}-\mathrm{H}), 7.35-7.43(\mathrm{~m}$, 5H, Ar-H), and 7.75-8.15 ( $m, 4 H, \mathrm{Ar}-\mathrm{H}) ; \mathrm{MS}(\mathrm{EI}) \mathrm{m} / \mathrm{z} \%: 332$ $\left(\mathrm{M}^{+}\right), 333\left(\mathrm{M}^{+}+1\right)$; IR cm ${ }^{-1}: 1,773(\mathrm{C}=\mathrm{O}), 1,651(\mathrm{C}=\mathrm{N})$; Anal. calcd for $\mathrm{C}_{20} \mathrm{H}_{13} \mathrm{FN}_{2} \mathrm{O}_{2}: \mathrm{C}, 72.28 ; \mathrm{H}, 3.94$; and N, 8.43. Found: $\mathrm{C}$, 72.19; H, 3.86; and N, 8.25. 


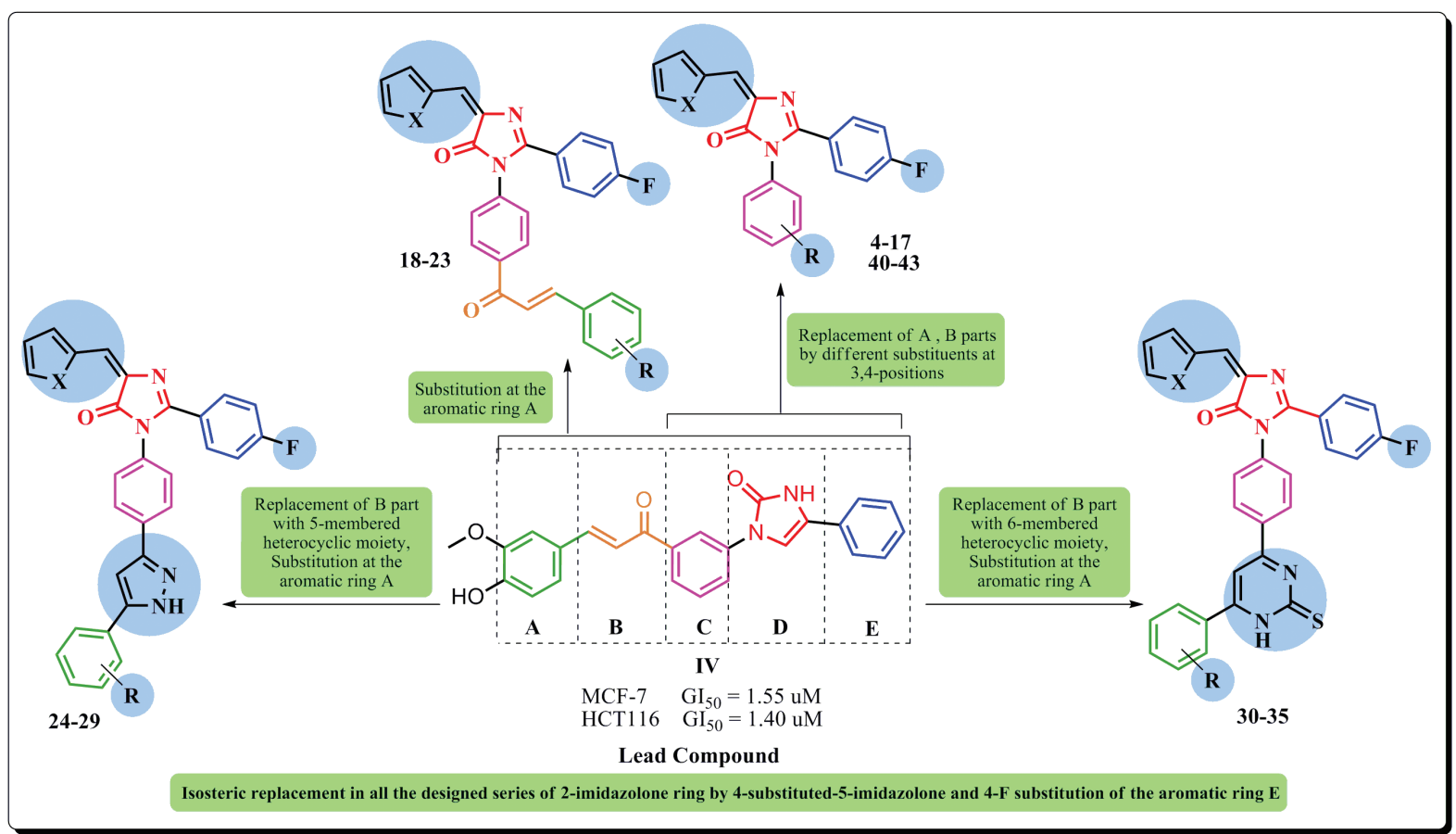

Figure 2. Molecular design of new imidazolones as anticancer agents based on structural modification of the lead compound IV.

(E)-1-(4-Bromophenyl)-2-(4-fluorophenyl)-4-(furan-2ylmethylene)-1H-imidazol-5(4H)-one (5)

Yield $60 \%$; mp $135^{\circ} \mathrm{C}-137^{\circ} \mathrm{C} ;{ }^{1} \mathrm{H}$ NMR (DMSO $d_{6}$ ): $7.15(s, 1 H$, olefinic-H), 7.35-7.78 ( $m, 3 H$, Ar-H), 7.85-8.10 (m, $4 H, \mathrm{Ar}-\mathrm{H})$, and $8.25-8.65(\mathrm{~m}, 4 \mathrm{H}, \mathrm{Ar}-\mathrm{H}) ; \mathrm{MS}(\mathrm{EI}) \mathrm{m} / \mathrm{z} \%: 410$ $\left(\mathrm{M}^{+}\right), 411\left(\mathrm{M}^{+}+1\right)$; IR cm $\mathrm{cm}^{-1}: 1,768(\mathrm{C}=\mathrm{O}), 1,645(\mathrm{C}=\mathrm{N})$; Anal. calcd for $\mathrm{C}_{20} \mathrm{H}_{12} \mathrm{BrFN}_{2} \mathrm{O}_{2}: \mathrm{C}, 5841 ; \mathrm{H}, 2.94$; and N, 6.81. Found: C, 58.36; H, 2.89; and N, 6.75.

(E)-2-(4-Fluorophenyl)-4-(furan-2-ylmethylene)-1-(4methylphenyl)-1H-imidazol-5(4H)-one (6)

Yield $55 \%$; mp $130{ }^{\circ} \mathrm{C}-132^{\circ} \mathrm{C}$; ${ }^{1} \mathrm{H}$ NMR (DMSO $d_{6}$ ): $2.45\left(s, 3 H, \mathrm{CH}_{3}\right), 6.85(s, 1 H$, olefinic-H), 7.18-7.35 ( $m, 3 H$, Ar-H), 7.45-7.64 ( $m, 4 H$, Ar-H), and 7.85-8.15 ( $m, 4 H$, Ar-H); MS (EI) m/z \%: $346\left(\mathrm{M}^{+}\right), 347\left(\mathrm{M}^{+}+1\right) ; \mathbf{I R ~ c m}^{-1}: 1,759(\mathrm{C}=\mathrm{O})$, $1,647(\mathrm{C}=\mathrm{N})$; Anal. calcd for $\mathrm{C}_{21} \mathrm{H}_{15} \mathrm{FN}_{2} \mathrm{O}_{2}: \mathrm{C}, 72.82 ; \mathrm{H}, 4.37$; and $\mathrm{N}, 8.09$. Found: $\mathrm{C}, 72.75 ; \mathrm{H}, 4.25$; and $\mathrm{N}, 8.15$.

(E)-2-(4-Fluorophenyl)-4-(furan-2-ylmethylene)-1-(3nitrophenyl)-1H-imidazol-5(4H)-one (7)

Yield $70 \%$; mp $145^{\circ} \mathrm{C}-147^{\circ} \mathrm{C} ;{ }^{1} \mathrm{H}$ NMR (DMSO $d_{6}$ ): $7.15(s, 1 H$, olefinic-H), 7.23-7.36 ( $m, 3 H$, Ar-H), 7.65-7.82 (m,

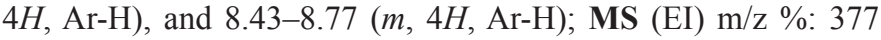
$\left(\mathrm{M}^{+}\right), 378\left(\mathrm{M}^{+}+1\right)$; IR cm ${ }^{-1}: 1,757(\mathrm{C}=\mathrm{O}), 1,644(\mathrm{C}=\mathrm{N})$; Anal. calcd for $\mathrm{C}_{20} \mathrm{H}_{12} \mathrm{FN}_{3} \mathrm{O}_{4}$ : C, 63.66; H, 3.21; and N, 11.14. Found: $\mathrm{C}$, 63.54; H, 3.15; and N, 11.20.

(E)-1-(3-Acetylphenyl)-2-(4-fluorophenyl)-4-(furan-2ylmethylene)-1H-imidazol-5(4H)-one (8)

Yield $65 \%$; mp $125^{\circ} \mathrm{C}-127^{\circ} \mathrm{C} ;{ }^{1} \mathrm{H}$ NMR (DMSO $d_{6}$ ): $2.35\left(s, 3 H, \mathrm{CH}_{3}\right), 7.13(s, 1 H$, olefinic-H), 7.18-7.37 ( $m, 3 H$, Ar-H), 7.45-7.87 ( $m, 4 H, \mathrm{Ar}-\mathrm{H})$, and 7.95-8.15 (m, 4H, Ar-H);
MS (EI) m/z \%: $374\left(\mathrm{M}^{+}\right), 375\left(\mathrm{M}^{+}+1\right)$; IR cm ${ }^{-1}: 1,750(\mathrm{C}=\mathrm{O})$, $1,652(\mathrm{C}=\mathrm{N})$; Anal. calcd for $\mathrm{C}_{22} \mathrm{H}_{15} \mathrm{FN}_{2} \mathrm{O}_{3}: \mathrm{C}, 70.58$; $\mathrm{H}, 4.04$; and $\mathrm{N}, 7.37$. Found: C, 70.45; H, 4.02; and N, 7.37.

(E)-1-(4-Acetylphenyl)-2-(4-fluorophenyl)-4-(furan-2ylmethylene)-1H-imidazol-5(4H)-one (9)

Yield $70 \%$; mp $130^{\circ} \mathrm{C}-132^{\circ} \mathrm{C} ;{ }^{1} \mathrm{H}$ NMR (DMSO $\left.d_{6}\right): 2.54\left(s, 3 H, \mathrm{CH}_{3}\right), 7.12(\mathrm{~s}, 1 \mathrm{H}$, olefinic-H), 7.23-7.36 (m, 4H, Ar-H), and 7.76-7.89 ( $m, 4 H$, Ar H); MS (EI) $m / z \%: 374$ $\left(\mathrm{M}^{+}\right), 375\left(\mathrm{M}^{+}+1\right) ;$ IR cm $\mathrm{cm}^{-1}: 1,761(\mathrm{C}=\mathrm{O})$ imidazolone, 1,685 $(\mathrm{C}=\mathrm{O})$ acetyl, 1,658 $(\mathrm{C}=\mathrm{N})$; Anal. calcd for $\mathrm{C}_{22} \mathrm{H}_{15} \mathrm{FN}_{2} \mathrm{O}_{3}$ : C, 70.58; H, 4.04; and N, 7.37. Found: C, 70.48; H, 4.02; and $\mathrm{N}, 7.32$.

(E)-Ethyl 4-[2-(4-fluorophenyl)]-4-(furan-2-ylmethylene)-5-oxo4,5-dihydro-1H-imidazol-1-yl)benzoate (10)

Yield $65 \%$; mp $170^{\circ} \mathrm{C}-173^{\circ} \mathrm{C} ;{ }^{1} \mathrm{H}$ NMR (DMSO $d_{6}$ ): $1.50\left(t, 3 \mathrm{H}, \mathrm{CH}_{3}\right), 4.35\left(q, 2 \mathrm{H}, \mathrm{CH}_{2}\right), 7.15(s, 1 H$, olefinic- $\mathrm{H})$, 7.20-7.35 ( $m, 3 H$, Ar-H), 7.44-7.67 ( $m, 4 H$, Ar-H), and 7.78-7.98 ( $m, 4 H$, Ar-H); MS (EI) m/z \%: $404\left(\mathrm{M}^{+}\right), 405\left(\mathrm{M}^{+}+1\right)$; IR cm ${ }^{-1}$ : 1,765 $(\mathrm{C}=\mathrm{O})$ imidazolone, 1,727 $(\mathrm{C}=\mathrm{O})$ ester, 1,657 $(\mathrm{C}=\mathrm{N})$; Anal. calcd for $\mathrm{C}_{23} \mathrm{H}_{17} \mathrm{FN}_{2} \mathrm{O}_{4}: \mathrm{C}, 68.31 ; \mathrm{H}, 4.24$; and N, 6.93. Found: $\mathrm{C}$, 68.23; H, 4.18; and N, 6.85.

(E)-2-(4-Fluorophenyl)-1-phenyl-4-(thiophen-2-ylmethylene)1H-imidazol-5(4H)-one (11)

Yield $71 \%$; mp $100^{\circ} \mathrm{C}-102{ }^{\circ} \mathrm{C} ;{ }^{1} \mathrm{H}$ NMR (DMSO $d_{6}$ ): $7.14(s, 1 H$, olefinic H), 7.23-7.34 ( $m, 3 H$, Ar-H), 7.45-7.58 (m, 5H, Ar-H), and 7.75-8.15 ( $m, 4 H, \mathrm{Ar}-\mathrm{H})$; MS (EI) $m / z \%: 348$ $\left(\mathrm{M}^{+}\right), 349\left(\mathrm{M}^{+}+1\right)$; IR cm ${ }^{-1}: 1,767(\mathrm{C}=\mathrm{O}), 1,662(\mathrm{C}=\mathrm{N})$; Anal. calcd for $\mathrm{C}_{20} \mathrm{H}_{13} \mathrm{FN}_{2} \mathrm{OS}$ : C, 68.95; H, 3.76; and N, 8.04. Found: C, 68.85 ; H, 3.65; and N, 8.02. 
(E)-1-(4-Bromophenyl)-2-(4-fluorophenyl)-4-(thiophen-2ylmethylene)-1H-imidazol-5(4H)-one (12)

Yield $65 \%$; mp $140{ }^{\circ} \mathrm{C}-142^{\circ} \mathrm{C} ;{ }^{1} \mathrm{H}$ NMR (DMSO $d_{6}$ ): $7.19(s, 1 H$, olefinic H), 7.43-7.78 ( $m, 3 H$, Ar-H), 7.87-8.10 ( $m$, $4 H, \mathrm{Ar}-\mathrm{H})$, and 8.36-8.65 ( $m, 4 H, \mathrm{Ar}-\mathrm{H})$; MS (EI) $m / z \%: 425$ $\left(\mathrm{M}^{+}\right), 426\left(\mathrm{M}^{+}+1\right)$; IR cm${ }^{-1}: 1,762(\mathrm{C}=\mathrm{O}), 1,671(\mathrm{C}=\mathrm{N})$; Anal. calcd for $\mathrm{C}_{20} \mathrm{H}_{12} \mathrm{BrFN}_{2} \mathrm{OS}$ : C, 56.22; H, 2.83; and $\mathrm{N}, 6.56$. Found: C, 56.15; H, 2.74; and N, 6.45.

(E)-2-(4-Fluorophenyl)-4-(thiophen-2-ylmethylene)-1-(4methylphenyl)-1H-imidazol-5(4H)-one (13)

Yield $75 \%$; mp $163^{\circ} \mathrm{C}-167^{\circ} \mathrm{C} ;{ }^{1} \mathrm{H}$ NMR (DMSO $\left.d_{6}\right)$ : $2.35\left(s, 3 H, \mathrm{CH}_{3}\right), 6.88(s, 1 H$, olefinic), 7.23-7.35 ( $m, 3 H, \mathrm{Ar}-\mathrm{H})$, 7.56-7.64 ( $m, 4 H, \mathrm{Ar}-\mathrm{H})$, and 7.85-8.12 ( $m, 4 H, \mathrm{Ar}-\mathrm{H})$; MS (EI) $m / z \%: 362\left(\mathrm{M}^{+}\right), 363\left(\mathrm{M}^{+}+1\right) ; \mathbf{I R ~ c m}{ }^{-1}: 1,762(\mathrm{C}=\mathrm{O}), 1,669$ $(\mathrm{C}=\mathrm{N})$; Anal. calcd for $\mathrm{C}_{21} \mathrm{H}_{15} \mathrm{FN}_{2} \mathrm{OS}$ : $\mathrm{C}, 69.59$; $\mathrm{H}, 4.17$; and $\mathrm{N}$, 7.73. Found: C, 69.4; H, 4.20; and N, 7.67.

(E)-2-(4-Fluorophenyl)-1-(3-nitrophenyl)-4-(thiophen-2ylmethylene)-1H-imidazol-5(4H)-one (14)

Yield $68 \%$; mp $142^{\circ} \mathrm{C}-145^{\circ} \mathrm{C} ;{ }^{1} \mathrm{H}$ NMR (DMSO $d_{6}$ ): $7.15(s, 1 H$, olefinic H), 7.23-7.45 ( $m, 3 H$, Ar-H), 7.65-7.82 ( $m$, 4H, Ar-H), and 8.36-8.77 ( $m, 4 H, \mathrm{Ar}-\mathrm{H})$; MS (EI) $m / z \%: 393$ $\left(\mathrm{M}^{+}\right), 394\left(\mathrm{M}^{+}+1\right)$; IR cm $\mathrm{cm}^{-1}$ 1,765 $(\mathrm{C}=\mathrm{O}), 1,666(\mathrm{C}=\mathrm{N})$; Anal. calcd for $\mathrm{C}_{20} \mathrm{H}_{12} \mathrm{FN}_{3} \mathrm{O}_{3} \mathrm{~S}: \mathrm{C}, 61.06 ; \mathrm{H}, 3.07$; and $\mathrm{N}, 10.68$. Found $\mathrm{C}, 61.15 ; \mathrm{H}, 3.11$; and $\mathrm{N}, 10.54$.

(E)-1-(3-Acetylphenyl)-2-(4-fluorophenyl)-4-(thiophen-2ylmethylene)-1H-imidazol-5(4H)-one (15)

Yield $71 \%$; mp $120^{\circ} \mathrm{C}-122^{\circ} \mathrm{C} ;{ }^{1} \mathrm{H}$ NMR (DMSO $d_{6}$ ): $2.53\left(s, 3 H, \mathrm{CH}_{3}\right), 6.98(s, 1 H$, olefinic-H), 7.02-7.14 ( $m, 3 H$, Ar H), 7.34-7.56 ( $m, 4 H, A r H)$, and 7.75-7.91 (m, 4H, Ar H); MS (EI) $m / z \%: 390\left(\mathrm{M}^{+}\right), 391\left(\mathrm{M}^{+}+1\right) ; \mathbf{I R ~ c m}{ }^{-1}: 1,768(\mathrm{C}=\mathrm{O})$, 1,684 $(\mathrm{C}=\mathrm{O})$ acetyl, 1,657 $(\mathrm{C}=\mathrm{N})$; Anal. calcd for $\mathrm{C}_{22} \mathrm{H}_{15} \mathrm{FN}_{2} \mathrm{O}_{2} \mathrm{~S}$ : C, 67.68; H, 3.87; and N, 7.18. Found: C, 67.54; H, 3.75; and N, 7.11 .

(E)-1-(4-Acetylphenyl)-2-(4-fluorophenyl)-4-(thiophen-2ylmethylene)-1H-imidazol-5(4H)-one (16)

Yield $75 \%$; mp $132^{\circ} \mathrm{C}-134^{\circ} \mathrm{C} ;{ }^{1} \mathrm{H}$ NMR (DMSO $d_{6}$ ): $2.52\left(s, 3 H, \mathrm{CH}_{3}\right), 6.92(s, 1 H$, olefinic-H), 7.23-7.41 ( $m, 8 H$, Ar-H), and 7.93-8.11 ( $m, 3 H, \mathrm{Ar}-\mathrm{H}) ;{ }^{13} \mathrm{C}$ NMR (DMSO $\left.d_{6}\right): \delta 20.7$, 89.4, 100.6, 110.5, 117.0, 120.3, 122.5, 127.5, 130.5, 132.3, 137.3, $140.8,144.6,148.3,153.9,156.2,158.0,166.0,169.6,177.6$, and 190.1; MS (EI) m/z \%: $390\left(\mathrm{M}^{+}\right), 391\left(\mathrm{M}^{+}+1\right) ; \mathbf{I R ~ c m} \mathrm{cm}^{-1}: 1,768$ $(\mathrm{C}=\mathrm{O})$ imidazolone, 1,687 $(\mathrm{C}=\mathrm{O})$ acetyl, 1,655 $(\mathrm{C}=\mathrm{N})$; Anal. calcd for $\mathrm{C}_{22} \mathrm{H}_{15} \mathrm{FN}_{2} \mathrm{O}_{2} \mathrm{~S}$ : C, 67.68; H, 3.87; and N, 7.18. Found: C, 67.58; H, 3.45; and N, 7.09.

(E)-Ethyl 4-[2-(4-fluorophenyl)-5-oxo-4-(thiophen-2-ylmethylene)4,5-dihydro-1H-imidazol-1-yl]benzoate (17)

Yield $69 \%$; mp $167^{\circ} \mathrm{C}-170^{\circ} \mathrm{C}$; ${ }^{1} \mathrm{H}$ NMR (DMSO $d_{6}$ ): $1.21\left(t, 3 \mathrm{H}, \mathrm{CH}_{3}\right), 4.27\left(q, 2 \mathrm{H}, \mathrm{CH}_{2}\right), 6.96(\mathrm{~s}, 1 \mathrm{H}$, olefinic- $\mathrm{H})$, 7.08-7.28 ( $m, 4 H, \mathrm{Ar} \mathrm{H})$, and 7.43-7.98 ( $m, 7 \mathrm{H}, \mathrm{Ar} \mathrm{H}) ;{ }^{13} \mathrm{CNMR}$ $\left(\mathrm{DMSO} d_{6}\right): \delta 10.7,25.4,100.2,113.5,114.3,117.4,118.5,120.6$, $123.7,124.2,125.7,126.5,127.4,130.3,133.5,142.3,147.4$, $152.7,153.9,155.3,160.4,166.7$, and 200.0, MS (EI) $\mathrm{m} / z \%$ : 420 $\left(17.5, \mathrm{M}^{+}\right)$; IR cm $\mathrm{cm}^{-1}$ : $1,759(\mathrm{C}=\mathrm{O})$ imidazolone, $1,725(\mathrm{C}=\mathrm{O})$ ester,
1,649 $(\mathrm{C}=\mathrm{N})$; Anal. calcd for $\mathrm{C}_{23} \mathrm{H}_{17} \mathrm{FN}_{2} \mathrm{O}_{3} \mathrm{~S}$ : C, 65.70; H, 4.08; and N, 6.66. Found: C, 65.45; H, 4.02; and N, 6.55.

\section{General procedure for synthesis of compounds 18-23}

A mixture of compound 9 or 19 (1 mmol) and different aromatic aldehydes $(1 \mathrm{mmol})$ was stirred in ethanolic sodium hydroxide solution $(5 \%, 10 \mathrm{ml})$ in ice bath for 4 hours, then the resulted precipitate was filtered, washed with aq. EtOH, and recrystallized from $\mathrm{EtOH}$.

(E)-2-(4-Fluorophenyl)-4-(furan-2-ylmethylene)-1-[4-(3phenylprop-2-enoyl)phenyl]-1H-imidazol-5(4H)-one (18)

Yield $50 \%$; mp $118^{\circ} \mathrm{C}-120^{\circ} \mathrm{C}$; ${ }^{1} \mathrm{H}$ NMR (DMSO $d_{6}$ ): $6.89(s, 1 H$, oleifinic H), 7.18-7.23 ( $m, 3 H, A r-H), 7.50(d, 1 H$, $\mathrm{C} \underline{\mathrm{H}}=\mathrm{CH}), 7.78(d, 1 H, \mathrm{CH}=\mathrm{CH}), 8.12-8.23(m, 4 H, \mathrm{Ar}-\mathrm{H}), 8.35$ $8.47(\mathrm{~m}, 4 \mathrm{H}, \mathrm{Ar}-\mathrm{H})$, and 8.76-9.11 ( $m, 5 H, \mathrm{Ar}-\mathrm{H})$; MS (EI) $\mathrm{m} / \mathrm{z} \%$ : $462.14\left(\mathrm{M}^{+}\right), 463\left(\mathrm{M}^{+}+1\right)$; IR cm $\mathrm{cm}^{-1}: 1,765(\mathrm{C}=\mathrm{O}), 1,655(\mathrm{C}=\mathrm{N})$; Anal. calcd for $\mathrm{C}_{29} \mathrm{H}_{19} \mathrm{FN}_{2} \mathrm{O}_{3}$ : C, 75.32; H, 4.14; and N, 6.06. Found: C, 75.32; H, 4.25; and N, 6.15.

(E)-\{4-[3-(3-Bromophenyl)prop-2-enoyl]phenyl $\}-2-(4-$ fluorophenyl)-4-(furan-2-ylmethylene)-1H-imidazol-5(4H)-one (19)

Yield $65 \%$; mp $115^{\circ} \mathrm{C}-117^{\circ} \mathrm{C} ;{ }^{1} \mathrm{H}$ NMR (DMSO $d_{6}$ ): $7.14(s, 1 H$, oleifinic H), 7.32-7.45 (m, 3H, Ar-H), $7.64(d, 1 H$, $\mathrm{C} \underline{\mathrm{H}}=\mathrm{CH}), 7.85(d, 1 H, \mathrm{CH}=\mathrm{C} \underline{\mathrm{H}}), 8.32-8.45(m, 4 H, A r-\mathrm{H})$, 8.67-8.98 ( $m, 4 H$, Ar-H), and 9.00-9.10 ( $m, 4 H$, Ar-H); MS (EI) $m / z \%$ : $540\left(\mathrm{M}^{+}\right), 541\left(\mathrm{M}^{+}+1\right) ; \mathbf{I R ~ c m}{ }^{-1}: 1,750(\mathrm{C}=\mathrm{O}), 1,661$ $(\mathrm{C}=\mathrm{N})$; Anal. calcd for $\mathrm{C}_{29} \mathrm{H}_{18} \mathrm{BrFN}_{2} \mathrm{O}_{3}: \mathrm{C}, 64.34 ; \mathrm{H}, 3.35$; and $\mathrm{N}$, 5.17. Found: C, 64.25; H, 3.15; and N, 5.26.

(E)-\{4-[3-(4-Chlorophenyl)prop-2-enoyl]phenyl $\}-2-(4-$ fluorophenyl)-4-(furan-2-ylmethylene)-1H-imidazol-5(4H)-one (20)

Yield $69 \%$; mp $120^{\circ} \mathrm{C}-122^{\circ} \mathrm{C} ;{ }^{1} \mathrm{H}$ NMR (DMSO $d_{6}$ ): $7.04(s, 1 H$, oleifinic-H), 7.27-7.36 (m, 3H, Ar-H), $7.78(d$, $1 H, \mathrm{CH}=\mathrm{CH}), 7.98(d, 1 H, \mathrm{CH}=\mathrm{CH}), 8.15-8.34(m, 4 H, \mathrm{Ar}-\mathrm{H})$, 8.48-8.67 ( $m, 4 H$, Ar-H), and 8.78-9.89 ( $m, 4 H$, Ar-H); MS (EI) $m / z$ \%: $496.10\left(\mathrm{M}^{+}\right), 497\left(\mathrm{M}^{+}+1\right)$; IR cm ${ }^{-1}: 1,755(\mathrm{C}=\mathrm{O}), 1,660$ $(\mathrm{C}=\mathrm{N})$; Anal. calcd for $\mathrm{C}_{29} \mathrm{H}_{18} \mathrm{ClFN}_{2} \mathrm{O}_{3}$ : C, 70.09; $\mathrm{H}, 3.65$; and $\mathrm{N}$, 5.64. Found: C, 70.45; H, 3.45; and N, 5.87.

(E)-2-(4-Fluorophenyl)-4-(thiophen-2-ylmethylene)-1-[4-(3phenylprop-2-enoyl)phenyl]-1H-imidazol-5(4H)-one (21)

Yield $55 \%$; mp $125^{\circ} \mathrm{C}-127^{\circ} \mathrm{C} ;{ }^{1} \mathrm{H}$ NMR (DMSO $d_{6}$ ): $7.36(s, 1 H$, oleifinic-H), $7.43(d, 1 H, \mathrm{CH}=\mathrm{CH}), 8.16(d, 1 H$ $\mathrm{CH}=\mathrm{CH}), 8.32-8.45$ ( $m, 4 H$, Ar-H), 8.67-8.98 ( $m, 4 H$, Ar-H), and 9.01-9.10 ( $m, 5 H, A r-H)$; MS (EI) $m / z \%: 478.54\left(\mathbf{M}^{+}\right)$; IR $\mathrm{cm}^{-1}$ : 1,757 $(\mathrm{C}=\mathrm{O}), 1,656(\mathrm{C}=\mathrm{N})$; Anal. calcd for $\mathrm{C}_{29} \mathrm{H}_{19} \mathrm{FN}_{2} \mathrm{O}_{2} \mathrm{~S}$ : C, 72.79; H, 4; and N, 5.85. Found: C, 72.45; H, 4.15; and N, 5.45.

(E)-\{4-[3-(3-Bromophenyl)prop-2-enoyl]phenyl $\}-2-(4-$ fluorophenyl)-4-(thiophen-2-ylmethylene)-1H-imidazol-5(4H)one (22)

Yield $60 \%$; mp $114^{\circ} \mathrm{C}-116^{\circ} \mathrm{C} ;{ }^{1} \mathrm{H}$ NMR (DMSO $d_{6}$ ): $7.36(s, 1 H$, oleifinic-H), $7.59(d, 1 H, \mathrm{CH}=\mathrm{CH}), 8.23(d, 1 H$, $\mathrm{CH}=\mathrm{C} \underline{\mathrm{H}}), 8.33-8.46$ ( $m, 4 H, \mathrm{Ar}-\mathrm{H}), 8.68-8.88(\mathrm{~m}, 4 H, \mathrm{Ar}-\mathrm{H})$, and 9.00-9.12 ( $m, 4 H$, Ar-H); MS (EI) $m / z \%: 557.43\left(\mathrm{M}^{+}\right)$; IR cm $\mathrm{cm}^{-1}$ : 
1,761 $(\mathrm{C}=\mathrm{O}), 1,650(\mathrm{C}=\mathrm{N})$; Anal. calcd for $\mathrm{C}_{29} \mathrm{H}_{18} \mathrm{BrFN}_{2} \mathrm{O}_{2} \mathrm{~S}: \mathrm{C}$, $62.48 ; \mathrm{H}, 3.25$; and $\mathrm{N}, 5.03$. Found: $\mathrm{C}, 62.35 ; \mathrm{H}, 3.15$; and $\mathrm{N}, 5.15$.

(E)-\{4-[3-(4-Chlorophenyl)prop-2-enoyl]phenyl $\}-2-(4-$ fluorophenyl)-4-(thiophen-2-ylmethylene)-1H-imidazol-5(4H)one (23)

Yield $67 \%$; mp $124^{\circ} \mathrm{C}-126^{\circ} \mathrm{C} ;{ }^{1} \mathrm{H}$ NMR (DMSO $d_{6}$ ): $7.09(s, 1 H$, olefinic-H), $7.87(d, 1 H, \mathrm{CH}=\mathrm{CH}), 8.43(d, 1 H$, $\mathrm{CH}=\mathrm{CH}), 8.32-8.45$ ( $m, 4 H, \mathrm{Ar}-\mathrm{H}), 8.67-8.98(m, 4 H, \mathrm{Ar}-\mathrm{H})$, and 9.02-9.10 ( $m, 4 H$, Ar-H); MS (EI) $m / z \%: 512.98\left(\mathrm{M}^{+}\right)$; IR cm ${ }^{-1}$ : $1,755(\mathrm{C}=\mathrm{O}), 1,657(\mathrm{C}=\mathrm{N})$; Anal. calcd for $\mathrm{C}_{29} \mathrm{H}_{18} \mathrm{ClFN}_{2} \mathrm{O}_{2} \mathrm{~S}: \mathrm{C}$, 67.9; H, 3.54; and N, 5.46. Found: C, 67.85; H, 3.34; and N, 5.67.

\section{General procedure for synthesis of compounds 24-29}

A mixture of the appropriate chalcone 18-23 (1mmol) and hydrazine hydrate $98 \%(1 \mathrm{mmol}, 0.03 \mathrm{ml})$ in abs. EtOH $(5 \mathrm{ml})$ was refluxed overnight followed by evaporation of the solvent, and then the product was neutralized with dil. $\mathrm{HCl}$. The precipitated product was filtered and dried after washing thoroughly with water.

(E)-2-(4-Fluorophenyl)-4-(furan-2-ylmethylene)-1-[4-(5-phenyl$1 \mathrm{H}$-pyrazol-3-yl)phenyl]-1H-imidazol-5(4H)-one (24)

Yield 50\%; mp $217^{\circ} \mathrm{C}-220^{\circ} \mathrm{C}$; ${ }^{1} \mathrm{H}$ NMR (DMSO $\left.d_{6}\right)$ : $6.51(s, 1 H$, pyrazole-H), $6.89(s, 1 H$, olefinic-H), $7.12-7.32(m$, $3 H$, Ar-H), 7.84-8.11 ( $m, 4 H$, Ar-H), 8.38-8.76 ( $m, 4 H$, Ar-H), 8.89-9.10 ( $m, 5 H, \mathrm{Ar}-\mathrm{H})$, and $12.45(\mathrm{~s}, 1 \mathrm{H}, \mathrm{NH}) ;{ }^{13} \mathrm{CNMR}$ (DMSO $\left.d_{6}\right): \delta 89.5,110.4,112.2,114.5,115.4,117.7,119.5,120.5,121.7$, $122.9,123.4,125.4,126.6,127.9,128.5,129.8,130.0,132.4$, $135.0,136.4,138.4,139.6,144.7,146.3,148.5,152.0,153.9$, 166.4, and 170.5; MS (EI) $m / z \%: 474\left(\mathrm{M}^{+}\right), 475\left(\mathrm{M}^{+}+1\right)$; IR $\mathrm{cm}^{-1}$ : 3,340 $(\mathrm{NH}), 1,750(\mathrm{C}=\mathrm{O}), 1,661(\mathrm{C}=\mathrm{N})$; Anal. calcd for $\mathrm{C}_{29} \mathrm{H}_{19} \mathrm{FN}_{4} \mathrm{O}_{2}$ : C, 73.41; H, 4.04; and N, 11.81. Found: C, 73.35; $\mathrm{H}, 4.15$; and $\mathrm{N}, 11.72$.

(E)-1-\{4-[5-(3-Bromophenyl)-1H-pyrazol-3-yl]phenyl\}-2-(4fluorophenyl)-4-(furan-2-ylmethylene)-1H-imidazol-5(4H)-one (25)

Yield 55\%; mp $198^{\circ} \mathrm{C}-200^{\circ} \mathrm{C} ;{ }^{1} \mathrm{H}$ NMR (DMSO $\left.d_{6}\right): 6.87(s, 1 H$, pyrazole-H), $7.14(s, 1 H$, olefinic-H), 7.24$7.65(\mathrm{~m}, 3 \mathrm{H}, \mathrm{Ar}-\mathrm{H}), 7.95-8.23$ ( $\mathrm{m}, 4 \mathrm{H}, \mathrm{Ar}-\mathrm{H}), 8.48-8.76(\mathrm{~m}$, 4H, Ar-H), 8.89-9.10 ( $m, 4 H, A r-H), 12.45(s, 1 H, \mathrm{NH})$, and $12.64(s, 1 H, \mathrm{NH})$; MS (EI) $m / z \%: 552\left(\mathrm{M}^{+}\right), 553\left(\mathrm{M}^{+}+1\right)$; IR $\mathrm{cm}^{-1}$ : 3,410 (NH), 1,759 $(\mathrm{C}=\mathrm{O}), 1,655(\mathrm{C}=\mathrm{N})$; Anal. calcd for $\mathrm{C}_{29} \mathrm{H}_{18} \mathrm{BrFN}_{4} \mathrm{O}_{2}$ : C, 62.94; $\mathrm{H}, 3.28$; and $\mathrm{N}, 10.12$. Found: $\mathrm{C}$, 62.87 ; H, 3.15; and N, 10.15 .

(E)-1-\{4-[5-(4-Chlorophenyl)-1H-pyrazol-3-yl]phenyl $\}-2-(4-$ fluorophenyl)-4-(furan-2-ylmethylene)- $1 \mathrm{H}$-imidazol-5(4H)-one (26)

Yield $56 \%$; mp $158^{\circ} \mathrm{C}-160^{\circ} \mathrm{C} ;{ }^{1} \mathrm{H}$ NMR (DMSO $d_{6}$ ): $7.04(s, 1 H$, pyrazole-H), $7.23(s, 1 H$, olefinic-H), 7.35-7.75 ( $m, 3 H$, Ar-H), 7.98-8.34 ( $m, 4 H$, Ar-H), 8.48-8.76 ( $m, 4 H$, Ar-H), 8.89-9.10 ( $m, 4 H$, Ar-H), 12.45 ( $s, 1 H, \mathrm{NH}), 12.64$ $(s, 1 H, \mathrm{NH})$, and $12.77(s, 1 H, \mathrm{NH}) ;{ }^{13} \mathrm{CNMR}$ (DMSO $\left.d_{6}\right): \delta$ $87.5,111.4,112.3,113.2,115.9,116.9,118.5,119.5,120.8$, $121.9,124.7,125.9,126.5,127.9,128.3,129.5,130.4,132.4$,
$135.0,137.4,138.4,139.6,143.7,145.3,147.5,152.0,153.9$, 166.4, and 170.5; MS (EI) $m / z \%: 508\left(\mathrm{M}^{+}\right), 509\left(\mathrm{M}^{+}+1\right)$; IR $\mathrm{cm}^{-1}$ : 3,310 (NH), 1,755 $(\mathrm{C}=\mathrm{O}), 1,661(\mathrm{C}=\mathrm{N})$; Anal. calcd for $\mathrm{C}_{29} \mathrm{H}_{18} \mathrm{ClFN}_{4} \mathrm{O}_{2}: \mathrm{C}, 68.44 ; \mathrm{H}, 3.56$; and N, 11.01. Found: C, $68.65 ; \mathrm{H}, 3.45$; and $\mathrm{N}, 11.15$.

(E)-2-(4-Fluorophenyl)-1-[4-(5-phenyl-1H-pyrazol-3-yl)phenyl]4-(thiophen-2-ylmethylene)-1H-imidazol-5(4H)-one (27)

Yield $56 \%$; mp $200^{\circ} \mathrm{C}-202^{\circ} \mathrm{C} ;{ }^{1} \mathrm{H}$ NMR (DMSO $d_{6}$ ): $6.45(\mathrm{~s}, 1 \mathrm{H}$, pyrazole-H), $7.12(\mathrm{~s}, 1 \mathrm{H}$, olefinic-H), $7.23-7.56(\mathrm{~m}$, 3H, Ar-H), 7.84-8.11 ( $m, 4 H$, Ar-H), 8.38-8.76 ( $m, 4 H$, Ar-H), 8.89-9.10 ( $m, 5 H, \mathrm{Ar}-\mathrm{H}), 12.45(s, 1 H, \mathrm{NH})$, and $12.45(s, 1 H$, NH); MS (EI) $m / z \%: 490\left(\mathrm{M}^{+}\right), 491\left(\mathrm{M}^{+}+1\right) ; \mathbf{I R ~ c m}{ }^{-1}: 3,410$ $(\mathrm{NH}), 1,754(\mathrm{C}=\mathrm{O}), 1,656(\mathrm{C}=\mathrm{N})$; Anal. calcd for $\mathrm{C}_{29} \mathrm{H}_{19} \mathrm{FN}_{4} \mathrm{OS}$ : C, 71; H, 3.9; and N, 11.42. Found: C, 71.15; H, 3.75; and N, 11.32 .

(E)-1-\{4-[5-(3-Bromophenyl)-1H-pyrazol-3-yl]phenyl $\}-2-(4-$ fluorophenyl)-4-(thiophen-2-ylmethylene)-1H-imidazol-5(4H)one (28)

Yield 59\%; mp $208^{\circ} \mathrm{C}-210^{\circ} \mathrm{C}$; ${ }^{1} \mathrm{H}$ NMR (DMSO $d_{6}$ ): $6.65(s, 1 H$, pyrazole-H), $6.87(s, 1 H$, olefinic-H), 7.24-7.65 ( $m, 3 H$, Ar-H), 7.95-8.23 ( $m, 4 H$, Ar-H), 8.48-8.76 ( $m, 4 H$, Ar$\mathrm{H}), 8.89-9.10(m, 4 H, \mathrm{Ar}-\mathrm{H}), 12.45(\mathrm{~s}, 1 \mathrm{H}, \mathrm{NH}), 12.64(\mathrm{~s}, 1 \mathrm{H}$, $\mathrm{NH})$, and $12.64(s, 1 H, \mathrm{NH})$; MS (EI) $m / z \%: 569.45\left(\mathrm{M}^{+}\right)$; IR $\mathrm{cm}^{-1}$ : 3,330 $(\mathrm{NH}), 1,758(\mathrm{C}=\mathrm{O}), 1,655(\mathrm{C}=\mathrm{N})$; Anal. calcd for $\mathrm{C}_{29} \mathrm{H}_{18} \mathrm{BrFN}_{4} \mathrm{OS}$ : C, 61.17; H, 3.19; and N, 9.84. Found: C, 61.23; $\mathrm{H}, 3.15$; and $\mathrm{N}, 9.78$.

(E)-1-\{4-[5-(4-Chlorophenyl)-1H-pyrazol-3-yl]phenyl\}-2-(4fluorophenyl)-4-(thiophen-2-ylmethylene)-1H-imidazol-5(4H)one (29)

Yield $58 \%$; mp $160^{\circ} \mathrm{C}-162^{\circ} \mathrm{C}$; ${ }^{1} \mathrm{H}$ NMR (DMSO $d_{6}$ ): $7.04(s, 1 H$, pyrazole-H), $7.23(s, 1 H$, olefinic-H), 7.35-7.75 ( $m$, $3 H$, Ar-H), 7.95-8.23 ( $m, 4 H$, Ar-H), 8.48-8.76 ( $m, 4 H$, Ar-H), 8.89-9.10 ( $m, 4 H, \mathrm{Ar}-\mathrm{H}), 12.45(s, 1 H, \mathrm{NH}), 12.64(s, 1 H, \mathrm{NH})$, and $12.77(s, 1 H, \mathrm{NH})$; MS (EI) $m / z \%: 524\left(\mathrm{M}^{+}\right), 525\left(\mathrm{M}^{+}+1\right)$; IR cm c $^{-1}: 3,350(\mathrm{NH}), 1,757(\mathrm{C}=\mathrm{O}), 1,662(\mathrm{C}=\mathrm{N})$; Anal. calcd for $\mathrm{C}_{29} \mathrm{H}_{18} \mathrm{ClFN}_{4} \mathrm{OS}$ : C, 66.35; H, 3.46; and N, 10.67. Found: $\mathrm{C}, 66.15$; $\mathrm{H}, 3.24$; and $\mathrm{N}, 10.87$.

\section{General procedure for synthesis of compounds 30-35}

To the solution of thiourea ( $1 \mathrm{mmol}, 0.076 \mathrm{~g})$ and sodium ethoxide in ethanol ( $5 \mathrm{ml})$, the appropriate chalcone18-23 (1 mmol) was added. The mixture was refluxed overnight. After cooling and evaporation of the solvent, the mixture was neutralized with dil. $\mathrm{HCl}$ and the precipitate was filtered and washed thoroughly with water.

(E)-2-(4-Fluorophenyl)-4-(furan-2-ylmethylene)-1-[4-(6-phenyl2-thioxo-1,2-dihydropyrimidin-4-yl)phenyl)]-1H-imidazol-5(4H)one (30)

Yield $53 \%$; mp $215^{\circ} \mathrm{C}-217^{\circ} \mathrm{C} ;{ }^{1} \mathrm{H}$ NMR (DMSO $d_{6}$ ): $6.23(s, 1 H$, pyrazole-H), $7.13(s, 1 H$, olefinic-H), 7.34-7.65 $(m$, $3 H, \mathrm{Ar}-\mathrm{H}), 7.75-7.89$ ( $m, 4 H, \mathrm{Ar}-\mathrm{H}), 8.15-8.23$ ( $m, 4 H, \mathrm{Ar}-\mathrm{H})$, 8.38-8.45 ( $m, 5 H, \mathrm{Ar}-\mathrm{H}), 12.45(s, 1 H, \mathrm{NH}), 12.64(s, 1 H, \mathrm{NH})$, and $13.65(s, 1 H, \mathrm{NH})$; MS (EI) $m / z \%: 518\left(\mathrm{M}^{+}\right), 519\left(\mathrm{M}^{+}+1\right)$; 
IR cm c $^{-1}: 3,310(\mathrm{NH}), 1,760(\mathrm{C}=\mathrm{O}), 1,654(\mathrm{C}=\mathrm{N})$; Anal. calcd for $\mathrm{C}_{30} \mathrm{H}_{19} \mathrm{FN}_{4} \mathrm{O}_{2} \mathrm{~S}$ : C, 69.48; H, 3.69; and N, 10.08. Found: C, 69.54; $\mathrm{H}, 3.59$; and N, 10.76 .

(E) - 1-\{4-[6-(3-Bromophenyl) - -sulfanylidene-1,2dihydropyrimidin-4-yl]phenyl\}-2-(4-fluorophenyl)-4-(furan-2ylmethylene)-1H-imidazol-5(4H)-one (31)

Yield $56 \%$; mp $218^{\circ} \mathrm{C}-220^{\circ} \mathrm{C} ;{ }^{1} \mathrm{H}$ NMR (DMSO $d_{6}$ ): $6.65(\mathrm{~s}, 1 \mathrm{H}$, pyrazole-H), $7.25(\mathrm{~s}, 1 \mathrm{H}$, olefinic-H), 7.34-7.78 $(\mathrm{m}$, 3H, Ar-H), 7.89-8.14 ( $m, 4 H$, Ar-H), 8.33-8.68 ( $m, 4 H$, Ar-H), 8.79-8.89 ( $m, 4 H, \mathrm{Ar}-\mathrm{H})$, and $13.45(\mathrm{~s}, 1 \mathrm{H}, \mathrm{NH})$; MS (EI) $m / z \%$ : $596\left(\mathrm{M}^{+}\right), 597\left(\mathrm{M}^{+}+1\right)$; IR cm $\mathrm{cm}^{-1}: 3,310(\mathrm{NH}), 1,758(\mathrm{C}=\mathrm{O}), 1,652$ $(\mathrm{C}=\mathrm{N})$; Anal. calcd for $\mathrm{C}_{30} \mathrm{H}_{18} \mathrm{BrFN}_{4} \mathrm{O}_{2} \mathrm{~S}: \mathrm{C}, 60.31 ; \mathrm{H}, 3.04$; and $\mathrm{N}$, 9.38. Found: C, 60.25; H, 3.54; and N, 9.48.

(E) - 1-\{4-[6-(4-Chlorophenyl)-2-sulfanylidene-1,2dihydropyrimidin-4-yl]phenyl\}-2-(4-fluorophenyl)-4-(furan-2ylmethylene)-1H-imidazol-5(4H)-one (32)

Yield $56 \%$; mp $162^{\circ} \mathrm{C}-164^{\circ} \mathrm{C} ;{ }^{1} \mathrm{H}$ NMR (DMSO $d_{6}$ ): $7.02(s, 1 H$, pyrazole-H), $7.35(s, 1 H$, olefinic-H), 7.44-7.78 $(m$, $3 H$, Ar-H), 7.98-8.17 ( $m, 4 H$, Ar-H), 8.37-8.58 ( $m, 4 H$, Ar-H), 8.79-8.89 ( $m, 4 H$, Ar-H), and $13.45(s, 1 H, \mathrm{NH})$; MS (EI) $m / z \%$ : $552\left(\mathrm{M}^{+}\right), 553\left(\mathrm{M}^{+}+1\right)$; IR cm ${ }^{-1}: 3,310(\mathrm{NH}), 1,762(\mathrm{C}=\mathrm{O}), 1,659$ $(\mathrm{C}=\mathrm{N})$; Anal. calcd for $\mathrm{C}_{30} \mathrm{H}_{18} \mathrm{ClFN}_{4} \mathrm{O}_{2} \mathrm{~S}: \mathrm{C}, 65.16$; $\mathrm{H}, 3.28$; and $\mathrm{N}$, 10.13. Found: C, 65.25; H, 3.15; and N, 10.27.

(E)-2-(4-Fluorophenyl)-1-[4-(6-phenyl-2-sulfanylidene-1,2dihydropyrimidin-4-yl)phenyl]-4-(thiophen-2-ylmethylene)- $1 \mathrm{H}$ imidazol-5(4H)-one (33)

Yield $55 \%$; mp $200{ }^{\circ} \mathrm{C}-203{ }^{\circ} \mathrm{C} ;{ }^{1} \mathrm{H}$ NMR (DMSO $\left.d_{6}\right)$ : $6.23(s, 1 H$, pyrazole-H), $7.13(s, 1 H$, olefinic-H), 7.34-7.65 ( $m, 3 H$, Ar-H), 7.75-7.89 ( $m, 4 H$, Ar-H), 8.15-8.23 ( $m, 4 H$, Ar-H), 8.38-8.45 ( $m, 5 H, A r-H)$, and $13.65(s, 1 H, \mathrm{NH})$; MS (EI) $m / z \%: 534\left(\mathrm{M}^{+}\right), 544\left(\mathrm{M}^{+}+1\right)$; IR cm ${ }^{-1}: 3,320(\mathrm{NH}), 1,757$ $(\mathrm{C}=\mathrm{O}), 1,665(\mathrm{C}=\mathrm{N})$; Anal. calcd for $\mathrm{C}_{30} \mathrm{H}_{19} \mathrm{FN}_{4} \mathrm{OS}_{2}$ : C, 67.4; H, 3.58; and N, 10.48. Found: C, 67.65; H, 3.45; and N, 10.35 .

(E) - 1-\{4-[6-(3-Bromophenyl) - - sulfanylidene-1,2dihydropyrimidin-4-yl]phenyl\}-2-(4-fluorophenyl)-4-(thiophen-2ylmethylene)-1H-imidazol-5(4H)-one (34)

Yield $59 \%$; mp $215^{\circ} \mathrm{C}-217^{\circ} \mathrm{C} ;{ }^{1} \mathrm{H}$ NMR (DMSO $\left.d_{6}\right)$ : $6.65(s, 1 H$, pyrazole-H), $7.25(s, 1 H$, olefinic-H), 7.34-7.78 (m, $3 H$, Ar-H), 7.89-8.14 ( $m, 4 H$, Ar-H), 8.33-8.68 ( $m, 4 H$, Ar-H), 8.79-8.89 ( $m, 4 H, \mathrm{Ar}-\mathrm{H})$, and $13.45(s, 1 H, \mathrm{NH})$; MS (EI) $m / z \%$ : $612\left(\mathrm{M}^{+}\right), 613\left(\mathrm{M}^{+}+1\right)$; IR cm ${ }^{-1}: 3,310(\mathrm{NH}), 1,753(\mathrm{C}=\mathrm{O}), 1,651$ $(\mathrm{C}=\mathrm{N})$; Anal. calcd for $\mathrm{C}_{30} \mathrm{H}_{18} \mathrm{BrFN}_{4} \mathrm{OS}$ : C, 58.73; $\mathrm{H}, 2.96$; and $\mathrm{N}$, 9.13. Found: C, 58.65; H, 2.45; and N, 9.15.

(E) - 1-\{4-[6-(4-Chlorophenyl)-2-sulfanylidene-1,2dihydropyrimidin-4-yl)]phenyl\}-2-(4-fluorophenyl)-4-(thiophen2-ylmethylene)-1H-imidazol-5(4H)-one (35)

Yield $58 \%$; mp $168^{\circ} \mathrm{C}-170^{\circ} \mathrm{C} ;{ }^{1} \mathrm{H}$ NMR (DMSO $d_{6}$ ): $7.02(s, 1 H$, pyrazole-H), $7.35(s, 1 H$, olefinic-H), 7.44-7.78 ( $\mathrm{m}$, $3 H$, Ar-H), 7.98-8.17 ( $m, 4 H$, Ar-H), 8.37-8.58 ( $m, 4 H$, Ar-H), 8.79-8.89 ( $m, 4 H, \mathrm{Ar}-\mathrm{H})$, and $13.45(\mathrm{~s}, 1 \mathrm{H}, \mathrm{NH})$; MS (EI) $m / z \%$ : $568\left(\mathrm{M}^{+}\right), 569\left(\mathrm{M}^{+}+1\right)$; IR cm ${ }^{-1}: 3,310(\mathrm{NH}), 1,760(\mathrm{C}=\mathrm{O}), 1,662$ $(\mathrm{C}=\mathrm{N})$; Anal. calcd for $\mathrm{C}_{30} \mathrm{H}_{18} \mathrm{ClFN}_{4} \mathrm{OS}$ : C, 67.10; H, 3.38; and $\mathrm{N}$, 10.43. Found: C, 67.23; H, 3.28; and N, 10.41.

\section{General procedure for synthesis of compounds 36-39}

A solution of the appropriate acetyl derivative (8, 9, 15, 16) $(1 \mathrm{mmol})$ in glacial acetic acid $(15 \mathrm{ml})$ was heated to $80^{\circ} \mathrm{C}-90^{\circ} \mathrm{C}$ with stirring. Bromine $(1 \mathrm{mmol}, 0.159 \mathrm{~g})$ was added drop by drop over 30 minutes to the hot mixture with stirring at $80^{\circ} \mathrm{C}-90^{\circ} \mathrm{C}$. After completion of bromine addition, the mixture continued to stir at room temperature for further 1 hour till evolution of hydrogen bromide gas was ceased. Then, it was poured over ice where the formed product was filtered, washed thoroughly with water, and recrystallized from $70 \%$ EtOH.

(E)-1-[3-(2-Bromoacetyl)phenyl]-2-(4-fluorophenyl)-4-(furan-2ylmethylene)-1H-imidazol-5(4H)-one (36)

Yield $69 \%$; mp $133^{\circ} \mathrm{C}-137^{\circ} \mathrm{C}$; ${ }^{1} \mathrm{H}$ NMR (DMSO $d_{6}$ ): $4.54\left(s, 2 \mathrm{H}, \mathrm{CH}_{2}\right), 7.27(s, 1 \mathrm{H}$, olefinic-H), 7.56-7.90 ( $\mathrm{m}, 3 \mathrm{H}$, Ar-H), and 8.00-8.11 ( $m, 8 H$, Ar H); MS (EI) $m / z \%: 452\left(\mathrm{M}^{+}\right)$, $453\left(\mathrm{M}^{+}+1\right)$; IR cm ${ }^{-1}: 1,765(\mathrm{C}=\mathrm{O}), 1,652(\mathrm{C}=\mathrm{N})$; Anal. calcd for $\mathrm{C}_{22} \mathrm{H}_{14} \mathrm{BrFN}_{2} \mathrm{O}_{3}$ : C, 56.3; H, 3.01; and N, 5.97. Found: C, 65.25; $\mathrm{H}, 3.53$; and N, 5.65 .

(E)-1-[4-(2-Bromoacetyl)phenyl]-2-(4-fluorophenyl)-4-(furan-2ylmethylene)-1H-imidazol-5(4H)-one (37)

Yield $68 \%$; mp $125^{\circ} \mathrm{C}-128^{\circ} \mathrm{C} ;{ }^{1} \mathrm{H}$ NMR (DMSO $d_{6}$ ): $4.67\left(s, 2 \mathrm{H}, \mathrm{CH}_{2}\right), 7.27(\mathrm{~s}, 1 \mathrm{H}$, olefinic-H), 7.56-7.78 $(\mathrm{m}, 3 \mathrm{H}$, Ar-H), and 7.92-8.11 ( $m, 8 H$, Ar H); MS (EI) $m / z \%: 452\left(\mathrm{M}^{+}\right)$, $453\left(\mathrm{M}^{+}+1\right)$; IR cm ${ }^{-1}: 1,761(\mathrm{C}=\mathrm{O}), 1,654(\mathrm{C}=\mathrm{N})$; Anal. calcd for $\mathrm{C}_{22} \mathrm{H}_{14} \mathrm{BrFN}_{2} \mathrm{O}_{3}: \mathrm{C}, 58.3$; H, 3.11; and N, 6.18. Found: C, 58.25; $\mathrm{H}, 3.15$; and $\mathrm{N}, 6.17$.

(E)-1-[3-(2-Bromoacetyl)phenyl]-2-(4-fluorophenyl)-4(thiophen-2-ylmethylene)-1H-imidazol-5(4H)-one (38)

Yield $73 \%$; mp $130{ }^{\circ} \mathrm{C}-133^{\circ} \mathrm{C} ;{ }^{1} \mathrm{H}$ NMR (DMSO $d_{6}$ ): $4.5\left(s, 2 H, \mathrm{CH}_{2}\right), 7.45(s, 1 H$, olefinic $\mathrm{H}), 7.56-7.67(m, 3 H$, Ar-H), and 7.88-8.23 ( $m, 8 H$, Ar H); ${ }^{13} \mathrm{CNMR}$ (DMSO $\left.d_{6}\right): \delta$ $29.4,107.6,114.7,115.9,118.7,124.9,125.9,127.5,129.5$, $131.5,132.9,133.0,134.7,135.9,136.5,138.5,139.3,140.5$, 158.4, 166.4, 168.2, and 200.5; MS (EI) $m / z \%: 467\left(\mathrm{M}^{+}\right), 468$ $\left(\mathrm{M}^{+}+1\right)$; IR cm ${ }^{-1}: 1,750(\mathrm{C}=\mathrm{O}), 1,656(\mathrm{C}=\mathrm{N})$; Anal. calcd for $\mathrm{C}_{22} \mathrm{H}_{14} \mathrm{BrFN}_{2} \mathrm{O}_{2} \mathrm{~S}$ : C, 56.3; H, 3.01; and N, 5.97. Found: C, 65.25; $\mathrm{H}, 3.53$; and $\mathrm{N}, 5.65$.

(E)-1-[4-(2-Bromoacetyl)phenyl]-2-(4-fluorophenyl)-4(thiophen-2-ylmethylene)-1H-imidazol-5(4H)-one (39)

Yield 70; mp $115^{\circ} \mathrm{C}-120^{\circ} \mathrm{C} ;{ }^{1} \mathrm{H}$ NMR (DMSO $\left.d_{6}\right): 4.3$ $\left(s, 2 \mathrm{H}, \mathrm{CH}_{2}\right), 7.45(s, 1 \mathrm{H}$, olefinic-H), 7.52-7.77 ( $m, 3 \mathrm{H}, \mathrm{Ar}-\mathrm{H})$, and 7.89-8.19 ( $m, 8 H$, Ar H); MS (EI) $m / z \%$ : $467\left(\mathrm{M}^{+}\right), 468$ $\left(\mathrm{M}^{+}+1\right)$; IR cm $\mathrm{cm}^{-1}: 1,762(\mathrm{C}=\mathrm{O}), 1,657(\mathrm{C}=\mathrm{N})$; Anal. calcd for $\mathrm{C}_{22} \mathrm{H}_{14} \mathrm{BrFN}_{2} \mathrm{O}_{2} \mathrm{~S}$ : C, 56.3; H, 3.01; and N, 5.97. Found: C, 65.25; $\mathrm{H}, 3.53$; and N, 5.65.

\section{General procedure for synthesis of compounds 40-43}

To a solution of the appropriate bromo derivative (36-39) $(1 \mathrm{mmol})$ in abs. EtOH $(20 \mathrm{ml})$, thiourea was added (1 mmol, $0.076 \mathrm{~g})$. The mixture was refluxed overnight, then it was cooled, followed by the addition of ammonium hydroxide. The precipitate was filtered and washed several times with water. 
(E)-1-[3-(2-Aminothiazol-4-yl)phenyl]-2-(4-fluorophenyl)-4(furan-2-ylmethylene)-1H-imidazol-5(4H)-one (40)

Yield $60 \%$; mp $260^{\circ} \mathrm{C}-262^{\circ} \mathrm{C} ;{ }^{1} \mathrm{H}$ NMR (DMSO $\left.d_{6}\right): 7.11\left(s, 2 H, \mathrm{NH}_{2}\right), 7.77-8.11(m, 8 H, \mathrm{Ar} \mathrm{H})$, and $7.36(s$, $1 \mathrm{H}$, olefinic-H); MS (EI) $m / z \%: 430\left(\% \mathrm{M}^{+}\right), 431\left(\mathrm{M}^{+}+1\right)$; IR $\mathrm{cm}^{-1}$ : 3,470 $\left(\mathrm{NH}_{2}\right), 1,753(\mathrm{C}=\mathrm{O}), 1,655(\mathrm{C}=\mathrm{N})$; Anal. calcd for $\mathrm{C}_{23} \mathrm{H}_{15} \mathrm{FN}_{4} \mathrm{O}_{2} \mathrm{~S}: \mathrm{C}, 61.87$; H, 3.39; and N, 12.55. Found: C, 61.74; $\mathrm{H}, 3.14$; and $\mathrm{N}, 12.45$.

(E)-1-[4-(2-Aminothiazol-4-yl)phenyl]-2-(4-fluorophenyl)-4(furan-2-ylmethylene)-1H-imidazol-5(4H)-one (41)

Yield 69\%; mp $243^{\circ} \mathrm{C}-245^{\circ} \mathrm{C}$; ${ }^{1} \mathrm{H}$ NMR (DMSO $d_{6}$ ): $7.24\left(s, 2 \mathrm{H}, \mathrm{NH}_{2}\right), 7.74-8.11(\mathrm{~m}, 8 \mathrm{H}, \mathrm{Ar} \mathrm{H})$, and $7.36(\mathrm{~s}, 1 \mathrm{H}$, olefinic-H); MS (EI) $m / z \%$ : $430\left(\% \mathrm{M}^{+}\right), 431\left(\mathrm{M}^{+}+1\right)$; IR cm ${ }^{-1}$ : 3,468 $\left(\mathrm{NH}_{2}\right), 1,761(\mathrm{C}=\mathrm{O})$, and $1,659(\mathrm{C}=\mathrm{N})$; Anal. calcd for $\mathrm{C}_{23} \mathrm{H}_{15} \mathrm{FN}_{4} \mathrm{O}_{2} \mathrm{~S}: \mathrm{C}, 64.87 ; \mathrm{H}, 3.51$; and $\mathrm{N}, 13.02$. Found: $\mathrm{C}, 64.25$; $\mathrm{H}, 3.45$; and $\mathrm{N}, 13.15$.

(E)-1-[3-(2-Aminothiazol-4-yl)phenyl]-2-(4-fluorophenyl)-4(thiophen-2-ylmethylene)-1H-imidazol-5(4H)-one (42)

Yield $55 \%$; mp $255^{\circ} \mathrm{C}-257^{\circ} \mathrm{C}$; ${ }^{1} \mathrm{H}$ NMR (DMSO $\left.d_{6}\right): 7.17\left(s, 2 H, \mathrm{NH}_{2}\right), 7.89-8.11(m, 8 H, \mathrm{Ar} \mathrm{H})$, and $7.36(s$, $1 \mathrm{H}$, olefinic-H); MS (EI) $\mathrm{m} / \mathrm{z} \%$ : $446\left(\% \mathrm{M}^{+}\right), 447\left(\mathrm{M}^{+}+1\right)$; IR $\mathrm{cm}^{-1}$ : 3,482 $\left(\mathrm{NH}_{2}\right), 1,763(\mathrm{C}=\mathrm{O}), 1,655(\mathrm{C}=\mathrm{N})$; Anal. calcd for $\mathrm{C}_{23} \mathrm{H}_{15} \mathrm{FN}_{4} \mathrm{OS}_{2}$ : C, 61.87; H, 3.39; and N, 12.55. Found: C, 61.74; $\mathrm{H}, 3.14$; and $\mathrm{N}, 12.45$.

(E)-1-[4-(2-Aminothiazol-4-yl)phenyl]-2-(4-fluorophenyl)-4(thiophen-2-ylmethylene)-1H-imidazol-5(4H)-one (43)

Yield $73 \%$; mp $256^{\circ} \mathrm{C}-258^{\circ} \mathrm{C}$; ${ }^{1} \mathrm{H}$ NMR (DMSO $d_{6}$ ): $7.65\left(s, 2 H, \mathrm{NH}_{2}\right), 7.75-8.11(\mathrm{~m}, 8 \mathrm{H}, \mathrm{Ar} \mathrm{H})$, and $7.36(s, 1 \mathrm{H}$, olefinic-H); MS (EI) $m / z \%$ : $446\left(\% \mathrm{M}^{+}\right), 447\left(\mathrm{M}^{+}+1\right)$; IR cm$~_{-1}$ : 3,475 $\left(\mathrm{NH}_{2}\right), 1,761(\mathrm{C}=\mathrm{O})$, and $1,656(\mathrm{C}=\mathrm{N})$; Anal. calcd for $\mathrm{C}_{23} \mathrm{H}_{15} \mathrm{FN}_{4} \mathrm{OS}_{2}$ : $\mathrm{C}, 61.87 ; \mathrm{H}, 3.39$; and $\mathrm{N}, 12.55$. Found: $\mathrm{C}, 61.74$; $\mathrm{H}, 3.14$; and $\mathrm{N}, 12.45$.

\section{Biological evaluation}

Preliminary in vitro cytotoxic screening

Cell lines: Four human tumor cell lines, namely, Epithelioid carcinoma (Hela), breast cancer (MCF-7), prostate cancer (PC3), and colorectal carcinoma (HCT-116) were obtained from ATCC through Holding company for biological products and vaccines (VACSERA), Cairo, Egypt.

Chemicals and reagents: The reagents used were RPMI-1640 medium, 3-(4,5-dimethylthiazol-2-yl)-2,5diphenyltetrazolium bromide (MTT) and DMSO (Sigma co., St. Louis, USA), and Fetal Bovine Serum (GIBCO, UK). Doxorubicin was used as a standard anticancer drug for comparison.

\section{MTT assay}

Cytotoxicity of the target compounds was determined via MTT assay on different cell lines. The assay depends on the conversion of yellow tetrazolium bromide (MTT) to a purple formazan derivative by mitochondrial succinate dehydrogenase. The process is initiated by culturing the cells in fetal bovine serum $(10 \%)$ mixed with RPMI-1640 medium. Both penicillin (100 units $/ \mathrm{ml})$ and streptomycin $(100 \mu \mathrm{g} / \mathrm{ml})$ were added in a $5 \% \mathrm{CO}_{2}$ incubator, at a temperature of $37^{\circ} \mathrm{C}$. Cells were grown at a density of $1.0 \times 10^{4}$ cells $/$ well at $37^{\circ} \mathrm{C}$ under $5 \% \mathrm{CO}_{2}$ in a 96-well plate for 48 hours. Cells were treated with various concentrations of the tested compounds after incubation, where they were further incubated for 24 hours. Thereafter, $20 \mu \mathrm{l}$ of MTT at $5 \mathrm{mg} / \mathrm{ml}$ was added and incubated for 4 hours. The dissolution of the purple formazan formed was achieved by the addition of $100 \mu$ l of DMSO into each well. The colorimetric assay was performed and recorded at $570 \mathrm{~nm}$ via a microplate reader (EXL 800, USA). \% Cell viability was then calculated as previously reported (Denizot and Lang, 1986; Mosmann, 1983).

\section{CDK2A enzyme assay}

Seven wells for standard and one well for blank were prepared. Add $100 \mu \mathrm{l}$ each of dilutions of standard (read reagent preparation), blank, and samples into the appropriate wells. Cover with the plate sealer. Incubate for 2 hours at $37^{\circ} \mathrm{C}$. Then, the liquid of each well was removed. After that, $100 \mu \mathrm{l}$ of detection reagent was added to each well and incubated for 1 hour at $37^{\circ} \mathrm{C}$ after covering with the plate sealer, followed by washing of each well with $350 \mu \mathrm{l}$ of the washing solution and left for 1-2 minutes. The remaining liquid was completely removed from all wells by snapping the plate onto absorbent paper, totally washed for three times, after which, any remaining wash buffer was removed, followed by plate inversion and blotting against absorbent paper. The previous process was repeated again using $100 \mu \mathrm{l}$ of detection reagent B working solution. Ninety miroliter of substrate solution was added to each well, covered with a new plate sealer and incubated for $15-25$ minutes at $37^{\circ} \mathrm{C}$. The liquid was turned blue by the addition of substrate solution. Then, the microplate reader was run and measurement was conducted at $450 \mathrm{~nm}$ immediately. Results were calculated by determination of the duplicate reading average for each standard, control, and samples, where the average zero standard optical density was subtracted. Then, construction of the standard curve was performed by plotting the mean O.D. and concentration for each standard, and a best-fit curve was drawn through the points on the graph or standard curve on log-log graph paper with CDK2 concentration on the $Y$-axis and absorbance on the $X$-axis was created.

\section{VEGFR-2 enzyme assay}

All reagents and samples were used at room temperature $\left(18^{\circ} \mathrm{C}-25^{\circ} \mathrm{C}\right)$. Both the standards and samples were run in duplicate, then $100 \mu \mathrm{l}$ of each standard and sample was added to the appropriate wells and incubated overnight at $4{ }^{\circ} \mathrm{C}$ with gentle shaking. The solution was washed four times with the washing solution, where any remaining wash buffer was removed. Plate inversion was performed, and then it was blotted. Each well was subjected to the addition of the biotinylated antibody $(100 \mu l)$ and then incubated for 1 hour at room temperature. After washing, the addition of the streptavidin solution $(100 \mu \mathrm{l})$ was made, followed by incubation for 45 minutes at room temperature. Also, $100 \mu \mathrm{l}$ of TMB (Item H) was added and then incubated for 30 minutes in the dark. Finally, $50 \mu \mathrm{l}$ of stop solution was added and read at $450 \mathrm{~nm}$. The mean absorbance for each set of duplicate standards, controls, and samples was calculated, and the average zero standard optical density was subtracted. Standard curve was drawn using Sigma 
plot software and then the best-fit straight line was drawn through the standard points.

\section{RESULTS AND DISCUSSION}

\section{Chemistry}

Imidazolone ring has a particular synthetic interest rather than the unique biological value owing to synthetic accessibility and structural variability. Besides, it constitutes the core structure of several natural compounds like histamine, histidine, biotin, alkaloids, and nucleic acids. It has been reported to be prepared by several methods, including the condensation of substituted azalactone with primary amines under anhydrous conditions (Kortiwala et al., 2016). In the present work, the synthetic pathways adopted for the preparation of the target new imidazolone derivatives are illustrated in Schemes 1-3.

4-Fluorobenzoyl chloride was subjected to nucleophilic condensation reaction with glycine in aq. $\mathrm{NaOH}$ to afford hippuric acid derivative $\mathbf{1}$ as the starting material. Oxazolone derivatives $\mathbf{2}$ and $\mathbf{3}$ were synthesized via Erlenmeyer condensation (El-Mekabaty, 2013; Erlenmeyer, 1900) of compound 1 with different heterocyclic aldehydes in acetic anhydride and glacial acetic acid. Disappearance of the broad band signal at $2,970 \mathrm{~cm}^{-1}$; that corresponds to the $(\mathrm{OH})$ of compound 1; in the IR spectrum of both compounds $\mathbf{2}$ and $\mathbf{3}$, in addition to the replacement of the $(\mathrm{C}=\mathrm{O})$ band at $1,720 \mathrm{~cm}^{-1}$ with $1,775-1,780 \mathrm{~cm}^{-1}$ confirmed the formation of the oxazolone ring. Subsequent reaction with different aromatic amines yielded the required imidazolone derivatives 4-17 (Scheme 1).

Chalcones 18-23 were synthesized from the acetyl derivatives 9 and $\mathbf{1 6}$ throughout Aldol condensation reaction with the proper aromatic aldehyde using $5 \% \mathrm{NaOH}$. The ${ }^{1} \mathrm{H}-\mathrm{NMR}$ spectrum reveals the appearance of two doublet peaks in the range of 7.50-8.06 ppm that correspond to the resulting olefinic protons.

These chalcones underwent different cyclization reactions either with hydrazine hydrate in absolute ethanol to afford the pyrazole derivatives 24-29 or with thiourea in the presence of sodium ethoxide to give the pyrimidines 30-35. The most diagnostic aspects in the ${ }^{1} \mathrm{HNMR}$ spectrum that confirmed the pyrazole ring cyclization were the disappearance of the two olefinic protons' signals and the appearance of a distinguishing singlet that corresponds to pyrazolyl ring proton at $6.5 \mathrm{ppm}$ (Scheme 2).

Compounds 8, 9, 15 and 16 were subjected to bromination in glacial acetic acid to afford compounds 36-39, which were treated with thiourea in the presence of absolute ethanol to give compounds 40-43. IR spectrum was characterized by the presence of $\mathrm{NH}$ band at $3,400 \mathrm{~cm}^{-1}$. In addition, ${ }^{1} \mathrm{HNMR}$ spectra were distinguish by the presence of a singlet signal at 7.11-7.65 ppm, corresponding to the protons of the $\mathrm{NH}_{2}$ group (Scheme 3).

\section{Biological evaluation}

\section{Preliminary in vitro cytotoxic screening}

In vitro cytotoxicity of all the synthesized imidazolonederivatives was evaluated against four tumor cell lines: Hela, MCF-7, PC3, and HCT-116, taking Doxorubicin (DOX.) as a control, where $\mathrm{IC}_{50}$ values were determined and listed in Table 1. Compounds $\mathbf{6}, \mathbf{2 5}, \mathbf{2 6}$, and 29 were shown to have the highest anticancer activities in the four cell lines in comparison to DOX. Concerning PC3 cell lines, compound $\mathbf{3 0}$ showed a cytotoxic effect compared to that of the standard with $\mathrm{IC}_{50}$ values of $8.15 \pm 0.9 \mu \mathrm{M}$, while compounds $\mathbf{4}$ and $\mathbf{1 8}$ showed moderate activity with $\mathrm{IC}_{50}$ range of 10.58-11.45 $\mu \mathrm{M}$. Regarding Hela and HCT-116 cell lines, compound $\mathbf{2 5}$ achieved the maximum cytotoxic activity with $\mathrm{IC}_{50}$ values of $7.34 \pm 0.5 \mu \mathrm{M}$ and $4.87 \pm$ 0.3 compared to $\mathrm{IC}_{50}$ values of $5.57 \pm 0.4 \mu \mathrm{M}$ and $5.23 \pm 0.2 \mu \mathrm{M}$ for DOX, respectively. On the other hand, compound 29 depicted the maximum effectiveness in MCF-7 and PC-3 cell lines with $\mathrm{IC}_{50}$ values of $6.27 \pm 0.4 \mu \mathrm{M}$ and $5.31 \pm 0.5 \mu \mathrm{M}$, respectively, whereas compound $\mathbf{6}$ reported the least anti-neoplastic activity among the four compounds. Interestingly, compound 29 was approximately twice as potent as Dox in PC3 cell line, while compound $\mathbf{2 5}$ was marginally better than the control in the HCT116 cell line (Fig. 3 ).

\section{CDK2A inhibition assay}

To evaluate the possible mode of action of the synthesized imidazolones as anticancer agents, compounds 6, 25, 26, and 29 were tested for both CDK2A and VEGFR-2 inhibitory activity using sorafenib as a reference drug. All substrates apart from 29 depicted a marginal rise in $\mathrm{IC}_{50}$ compared to sorafenib with compound 26 achieving the best result, followed by compounds 25 and 6. On the other hand, the $\mathrm{IC}_{50}$ of compound $\mathbf{2 9}$ skyrocketed up to $3.5 \mu \mathrm{M}$ making it the least effective (Table 2). These results indicated that CDK2A may be a possible target for the designed hybrids for their antineoplastic activity.

\section{VEGFR-2 enzyme assay}

Evaluating the inhibitory effect of compounds $\mathbf{6}, \mathbf{2 5}$, 26, and 29 on VEGFR-2 revealed excessively higher $\mathrm{IC}_{50}$ in comparison to sorafenib. $\mathrm{IC}_{50}$ ranged from as low as treble that of sorafenib in compound 6, up to approximately 8 folds in compound 29 (Table 2).

\section{SAR discussion}

Several imidazolone hybrids were synthesized and evaluated for their cytotoxicity against four cancer cell lines, namely, Hela, MCF-7, PC3, and HCT-116. Enzyme inhibitory activity against CDK2A as well as VEGFR-2 was also investigated. Two compounds from the first series which embraces furanylmethylene-imidazolone 4-10 showed considerable cytotoxic activity, where the unsubstituted phenyl derivative 4 exhibited moderate activity against $\mathrm{PC} 3$ cell lines with an $\mathrm{IC}_{50}$ value of $11.45 \pm 1.2 \mu \mathrm{M}$, while the 4-methylphenyl derivative 6 showed good and broad-spectrum activity against the tested cell lines. The thiophenyl methylene-imidazolone series 11-17 exhibited weak to no activity. Regarding the imidazolone hybrids containing chalcone moiety 18-23, compound 18 showed moderate activity against PC3 cell lines with an $\mathrm{IC}_{50}$ value of $10.85 \pm 1.1 \mu \mathrm{M}$. The series that involves the pyrazolyl derivatives 24-29 was the most promising regarding the anticancer activity with three potent compounds 25, 26, and 29, having broad activity against all cell lines. On the other hand, hybrids containing the pyrimidinethione derivatives 30-35 provided compound $\mathbf{3 0}$ with anticancer activity compared to that of the standard DOX against PC3 cell lines. The 


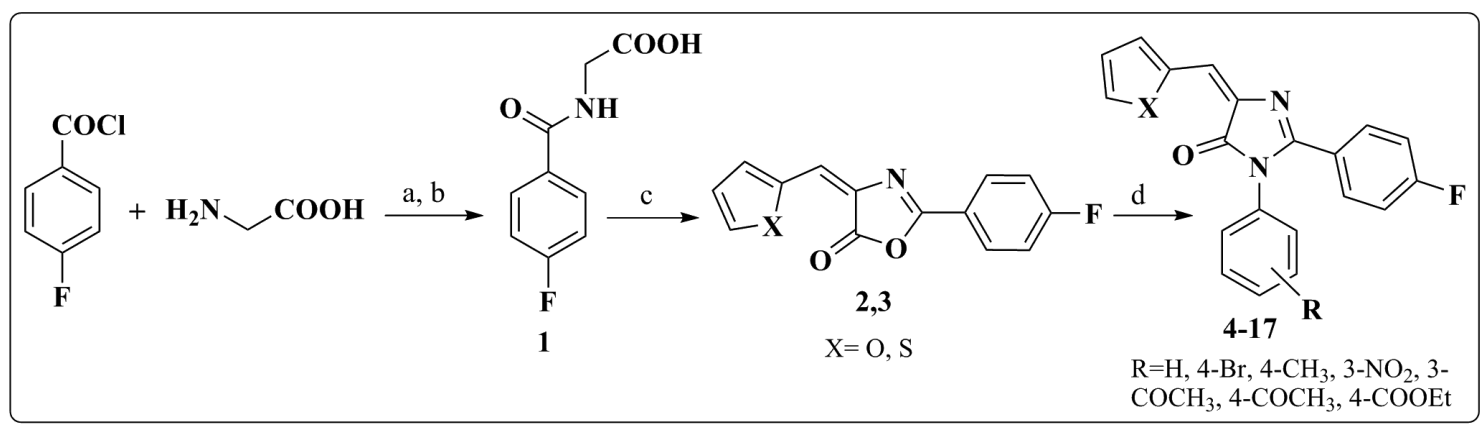

Scheme 1. Synthesis of compounds 2-17. Reagents and Conditions: (a) 10\% NaOH, stirring, 2 hours; (b) conc. $\mathrm{HCl}$; (c) the appropriate heterocyclic aldehyde, NaOAc, glacial acetic acid, reflux; (d) the appropriate aromatic amine, NaOAc/glacial acetic acid, heat/water bath.

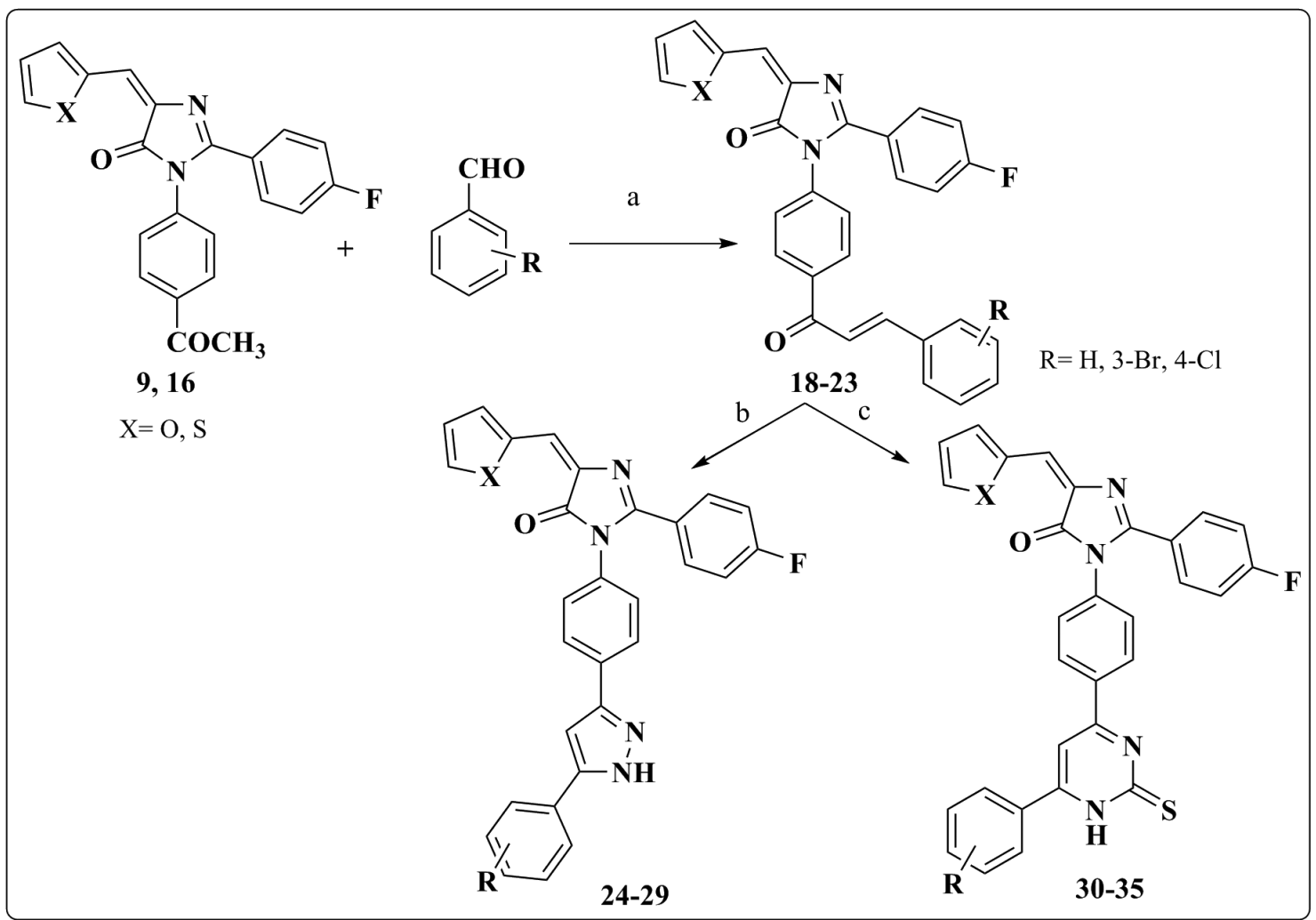

Scheme 2. Synthesis of compounds 18-35. Reagents and Conditions: (a) $5 \%$ ethanolic $\mathrm{NaOH}$, stirring, ice bath, $4 \mathrm{~h}$; (b) $\mathrm{NH}_{2} \mathrm{NH}_{2} \cdot \mathrm{H}_{2} \mathrm{O}$, abs. EtOH, reflux; (c) thiourea, NaOEt, reflux.

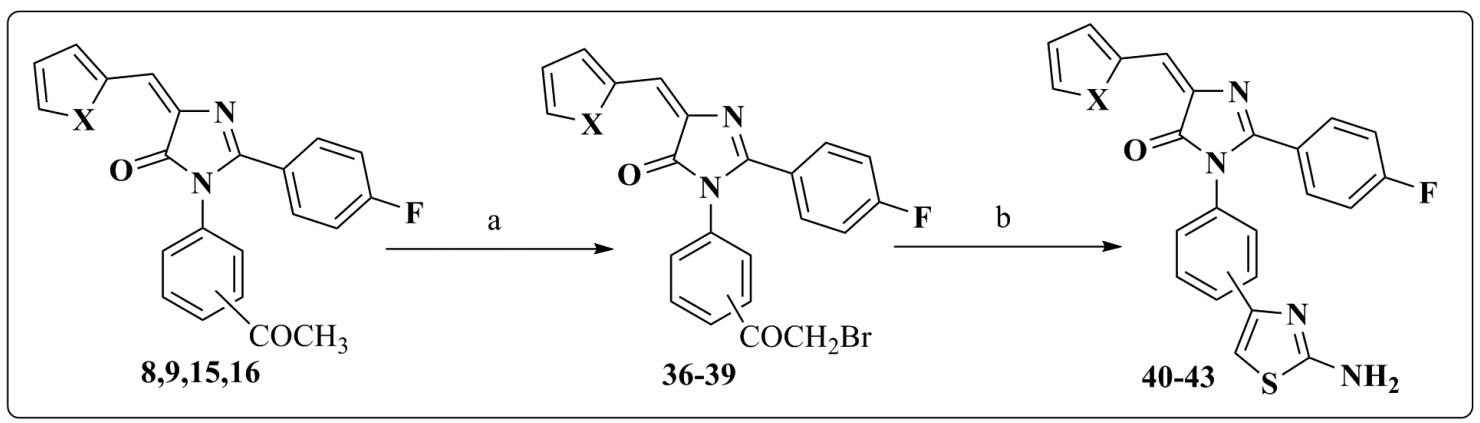

Scheme 3. Synthesis of compounds 36-43. Reagents and Conditions: (a) $\mathrm{Br}_{2}$, glacial acetic acid, $80^{\circ} \mathrm{C}-90^{\circ} \mathrm{C}$; (b) thiourea, abs. EtOH, reflux. 
Table 1. $\mathrm{IC}_{50}$ of the target compounds against Hela, MCF-7, PC3, and HCT-116cell lines.

\begin{tabular}{|c|c|c|c|c|c|c|c|c|c|}
\hline \multirow{2}{*}{ Comp. no. } & \multicolumn{4}{|c|}{$\mathrm{IC}_{50}(\mu \mathrm{M})$} & \multirow{2}{*}{ Comp. no. } & \multicolumn{4}{|c|}{$\mathrm{IC}_{50}(\mu \mathrm{M})$} \\
\hline & Hela & MCF-7 & PC3 & HCT-116 & & Hela & MCF-7 & PC3 & HCT-116 \\
\hline 2 & $97.81 \pm 5.3$ & $47.84 \pm 3.2$ & $43.79 \pm 3.2$ & $>100$ & 24 & $14.83 \pm 1.1$ & $11.72 \pm 1.2$ & $16.89 \pm 1.5$ & $13.70 \pm 1.1$ \\
\hline 4 & $16.28 \pm 1.3$ & $10.36 \pm 1.1$ & $11.45 \pm 1.2$ & $14.56 \pm 1.3$ & 25 & $7.34 \pm 0.5$ & $7.58 \pm 0.6$ & $6.64 \pm 0.6$ & $4.87 \pm 0.3$ \\
\hline 5 & $36.12 \pm 2.2$ & $15.81 \pm 1.4$ & $17.50 \pm 1.6$ & $38.63 \pm 2.0$ & 26 & $8.86 \pm 0.8$ & $7.83 \pm 0.7$ & $7.26 \pm 0.7$ & $6.81 \pm 0.6$ \\
\hline 6 & $10.11 \pm 0.9$ & $8.67 \pm 0.7$ & $9.80 \pm 1.1$ & $7.55 \pm 0.8$ & 27 & $24.51 \pm 1.7$ & $20.16 \pm 1.6$ & $30.80 \pm 2.4$ & $22.43 \pm 1.6$ \\
\hline 7 & $94.67 \pm 4.9$ & $95.37 \pm 5.1$ & $>100$ & $>100$ & 28 & $13.07 \pm 1.1$ & $9.70 \pm 1.0$ & $15.01 \pm 1.4$ & $11.42 \pm 0.9$ \\
\hline 8 & $46.56 \pm 3.1$ & $22.87 \pm 1.8$ & $21.57 \pm 1.9$ & $52.83 \pm 2.5$ & 29 & $7.91 \pm 0.6$ & $6.27 \pm 0.4$ & $5.31 \pm 0.5$ & $5.93 \pm 0.6$ \\
\hline 9 & $>100$ & $93.62 \pm 4.8$ & $>100$ & $>100$ & 30 & $21.35 \pm 1.6$ & $9.48 \pm 0.9$ & $8.15 \pm 0.9$ & $17.36 \pm 1.5$ \\
\hline 10 & $60.41 \pm 3.5$ & $29.84 \pm 2.4$ & $37.47 \pm 2.9$ & $64.62 \pm 3.1$ & 31 & $19.35 \pm 1.4$ & $23.61 \pm 1.8$ & $31.85 \pm 2.5$ & $16.49 \pm 1.3$ \\
\hline 11 & $91.49 \pm 4.8$ & $88.25 \pm 4.2$ & $86.91 \pm 4.4$ & $97.18 \pm 5.7$ & 32 & $38.24 \pm 2.4$ & $13.66 \pm 1.3$ & $12.71 \pm 1.3$ & $41.95 \pm 2.0$ \\
\hline 12 & $84.59 \pm 4.4$ & $90.50 \pm 4.5$ & $>100$ & $91.74 \pm 4.9$ & 33 & $65.14 \pm 3.8$ & $50.10 \pm 3.3$ & $59.84 \pm 3.7$ & $73.74 \pm 3.5$ \\
\hline 13 & $63.82 \pm 3.6$ & $61.06 \pm 3.4$ & $64.08 \pm 3.8$ & $68.11 \pm 3.2$ & 34 & $81.56 \pm 4.3$ & $80.41 \pm 3.8$ & $69.47 \pm 3.9$ & $87.83 \pm 4.7$ \\
\hline 14 & $51.34 \pm 3.0$ & $37.08 \pm 2.8$ & $48.60 \pm 3.4$ & $54.49 \pm 2.7$ & 35 & $57.19 \pm 3.4$ & $25.81 \pm 1.9$ & $13.43 \pm 1.3$ & $62.31 \pm 2.9$ \\
\hline 15 & $43.87 \pm 2.6$ & $32.62 \pm 2.5$ & $33.32 \pm 2.8$ & $44.90 \pm 2.3$ & 36 & $79.47 \pm 4.2$ & $28.13 \pm 2.3$ & $25.04 \pm 2.3$ & $85.19 \pm 4.1$ \\
\hline 16 & $71.20 \pm 3.9$ & $39.57 \pm 2.9$ & $41.50 \pm 3.1$ & $78.16 \pm 3.8$ & 37 & $>100$ & $>100$ & $>100$ & $>100$ \\
\hline 17 & $68.01 \pm 3.8$ & $82.62 \pm 4.0$ & $78.53 \pm 4.2$ & $77.25 \pm 3.6$ & 38 & $87.21 \pm 4.6$ & $56.92 \pm 3.4$ & $51.62 \pm 3.5$ & $92.80 \pm 5.0$ \\
\hline 18 & $46.10 \pm 2.9$ & $12.59 \pm 1.2$ & $10.58 \pm 1.1$ & $50.76 \pm 2.4$ & 39 & $>100$ & $>100$ & $>100$ & $>100$ \\
\hline 19 & $29.23 \pm 1.8$ & $15.37 \pm 1.4$ & $16.97 \pm 1.5$ & $32.01 \pm 1.7$ & 40 & $31.40 \pm 1.9$ & $17.63 \pm 1.5$ & $18.61 \pm 1.7$ & $34.55 \pm 1.8$ \\
\hline 20 & $33.58 \pm 2.0$ & $18.85 \pm 1.6$ & $19.83 \pm 1.8$ & $36.78 \pm 1.9$ & 41 & $40.53 \pm 2.5$ & $26.49 \pm 2.0$ & $35.06 \pm 2.8$ & $42.72 \pm 2.1$ \\
\hline 21 & $54.72 \pm 3.3$ & $27.50 \pm 2.1$ & $22.39 \pm 1.9$ & $57.08 \pm 2.8$ & 42 & $74.48 \pm 4.0$ & $34.81 \pm 2.7$ & $45.31 \pm 3.3$ & $82.81 \pm 3.9$ \\
\hline 22 & $76.36 \pm 4.1$ & $45.42 \pm 3.1$ & $55.91 \pm 3.5$ & $83.97 \pm 4.2$ & 43 & $27.03 \pm 1.8$ & $22.03 \pm 1.7$ & $24.78 \pm 2.1$ & $28.64 \pm 1.7$ \\
\hline 23 & $89.40 \pm 4.7$ & $72.65 \pm 3.8$ & $75.12 \pm 3.9$ & $96.02 \pm 5.3$ & DOX & $5.57 \pm 0.4$ & $4.17 \pm 0.2$ & $8.87 \pm 0.6$ & $5.23 \pm 0.2$ \\
\hline
\end{tabular}

DOX: Doxorubicin.

Data are presented as the mean \pm SDs of three independent experiments.

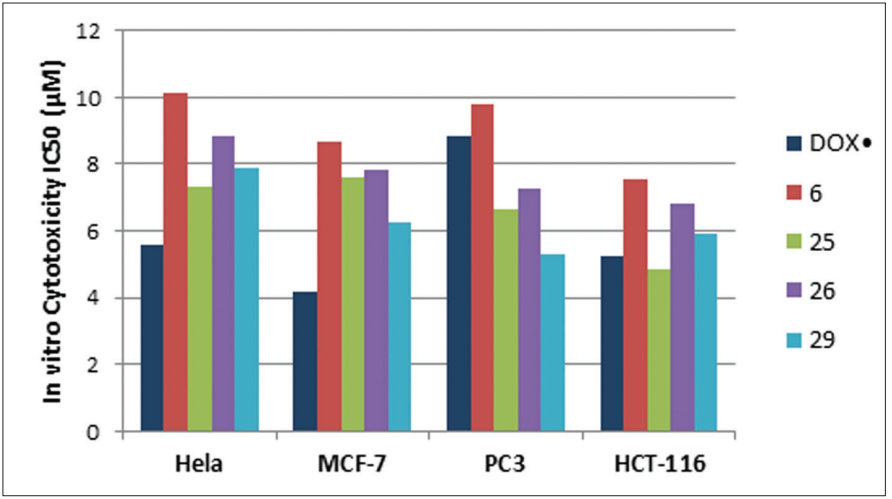

Figure 3. Cytotoxic activity of compounds $6,25,26$, and 29 compared to Dox.

last series 36-43 with the aminothiazole substitution showed low activity.

Concerning the enzyme inhibitory activity against both CDK2A and VEGFR-2, compounds 6, 25, 26, and 29 showed various activities, related to the structural features characterizing them. Investigation into the SAR of the target compounds revealed that furanylmethylene-imidazolone hybrids $\mathbf{6}, \mathbf{2 5}$, and 26 exhibited considerable enzyme inhibition rather than the thiophenyl methylene-imidazolone hybrid 29, where compound 26 showed an $\mathrm{IC}_{50}$ value of $92 \pm 1.57 \mathrm{nM}$ (for VEGFR-2) and $0.66 \pm 0.03 \mu \mathrm{M}$ (for CDK2A) on HCT116 cell line, respectively. Likewise, compound 6 with an $\mathrm{IC}_{50}$ value of $67 \pm 0.89 \mathrm{nM}$ (for
Table 2. CDK2A and VEGFR-2 $\mathrm{IC}_{50}$ of compounds 6, 25, 26, and 29 compared to sorafenib.

\begin{tabular}{lccccc}
\hline \multirow{2}{*}{ Enzyme } & $\mathbf{5}$ Comp. \\
\cline { 2 - 6 } & $\mathbf{6}$ & $\mathbf{2 5}$ & $\mathbf{2 6}$ & $\mathbf{2 9}$ & Sorafinib \\
\hline $\begin{array}{l}\text { VEGFR-2 (Cell } \\
\text { line: HCT116) }\end{array}$ & $67 \pm 0.89$ & $158 \pm 0.87$ & $92 \pm 1.57$ & $177 \pm 1.15$ & $21 \pm 0.72$ \\
$\begin{array}{l}\mathrm{IC}_{50}(\mathrm{nM}) \\
\text { CDK2A (Cell }\end{array}$ & & & & & \\
line: HCT116) & $1.14 \pm 0.14$ & $0.83 \pm 0.04$ & $0.66 \pm 0.03$ & $3.55 \pm 0.09$ & $0.37 \pm 0.02$ \\
$\mathrm{IC}_{50}(\mu \mathrm{M})$ & & & & & \\
\hline
\end{tabular}

Data are presented as the mean \pm SDs of three independent experiments.

VEGFR-2) and compound 25 with an $\mathrm{IC}_{50}$ value of $0.83 \pm 0.04$ $\mu \mathrm{M}$ (for CDK2A) came next. It was observed that compound 6 demonstrated the highest inhibitory effect when compared to other compounds on VEGFR-2 and moderate effect on CDK2A enzyme. On the other hand, compound 29 yielded the lowest inhibitory activity on both tested enzymes. Conversely, when thiophene ring of compound $\mathbf{2 9}$ was replaced by furfural ring and the 3-bromophenyl group substituted the 4-chlorophenyl group in compound 25, the inhibitory effect was moderate against CDK2A enzyme. Interestingly, as 3-bromophenyl moiety was replaced by 4-chlorophenyl moiety in the presence of furfural ring in compound 26, the inhibitory effect was demonstrated on both VEGFR-2 and CDK2A enzymes suggesting a powerful anti-cancer effect.

To sum up, compounds $\mathbf{2 5}$ and $\mathbf{2 6}$ are more likely to produce their effects on the molecular enzymatic level rather than inhibiting cell surface receptors. 


\section{CONCLUSION}

Compounds 6, 25, 26, and 29 were shown to have the highest anticancer activities in the four cell lines in comparison to DOX. Concerning PC3 cell lines, compound $\mathbf{3 0}$ showed a cytotoxic effect comparable to that of the standard. Compounds $\mathbf{6}$, $\mathbf{2 5}$, and $\mathbf{2 6}$ depicted a marginal rise in $\mathrm{IC}_{50}$ compared to sorafenib, with compound $\mathbf{2 6}$ achieving the best result regarding CDK2A and VEGFR-2 inhibitory activity.

\section{CONFLICT OF INTEREST}

The authors confirm that this article content has no conflict of interest.

\section{REFERENCES}

Ajeesh Kumar A.K, Bodke YD, Gowda AN, Sambasivam G, Bhat KG. Design, synthesis, and evaluation of the anticancer properties of a novel series of imidazolone fused pyrazolo[1,5-a]pyrimidine derivatives. J Heterocyclic Chem, 2017; 54:1904-24.

Akhtar J, Khan AA, Ali Z, Haider R, Shahar Yar M. Structure-activity relationship (SAR) study and design strategies of nitrogen-containing heterocyclic moieties for their anticancer activities. Eur J Med Chem, 2017; 125:143-89.

Denizot F, Lang R. Rapid colorimetric assay for cell growth and survival. Modifications to the tetrazolium dye procedure giving improved sensitivity and reliability. J Immunol Methods, 1986; 89:271-7.

Dražić T, Vazdar K, Vazdar M, Đaković M, Mikecin AM, Kralj M, Malnar M, Hećimović S, Habuš I. Synthesis of new 2-aminoimidazolones with antiproliferative activity via base promoted amino- $\beta$-lactam rearrangement. Tetrahedron, 2015; 71:9202-15.

El-Araby M, Omar A, Hassanein HH, El-Helby A-GH, Abdel-Rahman AA. Design, synthesis and in vivo anti-inflammatory activities of 2,4-diaryl-5-4H-imidazolone derivatives. Molecules, 2012; 17:12262.

El-Mekabaty A. Erlenmeyer azlactones: synthesis, reactions and biological activity. Int J Modern Org Chem, 2013; 2:40-66.

Erlenmeyer E. Ueber die partielle verwandlung der phenyloxyacrylsäure in phenylbrenztraubensäure. Eur J Inorg Chem, 1900; 33:3001-2.

Kalyanaraman B. Teaching the basics of cancer metabolism: Developing antitumor strategies by exploiting the differences between normal and cancer cell metabolism. Redox Biol, 2017; 12:833-42.

Kamal A, Ramakrishna G, Raju P, Viswanath A, Ramaiah MJ, Balakishan G, Pal-Bhadra M. Synthesis and anti-cancer activity of chalcone linked imidazolones. Bioorg Med Chem Lett, 2010; 20:4865-9.

Kortiwala N, Patel J, Desai VA. Imidazolone and its various biological activities-a review. J Chem Chem Sci, 2016; 6:25-32.

Kumar D, Mariappan G, Husain A, Monga J, Kumar S. Design, synthesis and cytotoxic evaluation of novel imidazolone fused quinazolinone derivatives. Arab J Chem, 2017; 10:344-50.

Mahapatra DK, Bharti SK, Asati V. Anti-cancer chalcones: structural and molecular target perspectives. Eur J Med Chem, 2015; 98: $69-114$

Mai CW, Yaeghoobi M, Abd-Rahman N, Kang YB, Pichika MR. Chalcones with electron-withdrawing and electron-donating substituents: anticancer activity against TRAIL resistant cancer cells, structure-activity relationship analysis and regulation of apoptotic proteins. Eur J Med Chem, $2014 ; 77: 378-87$.
Mosmann T. Rapid colorimetric assay for cellular growth and survival: application to proliferation and cytotoxicity assays. J Immunol Methods, 1983; 65:55-63.

Nasir Abbas Bukhari S, Jasamai M, Jantan I, Ahmad W. Review of methods and various catalysts used for chalcone synthesis. Mini Rev Org Chem, 2013; 10:73-83.

Padmaja A, Rajasekhar C, Muralikrishna A, Padmavathi V. Synthesis and antioxidant activity of oxazolyl/thiazolylsulfonylmethyl pyrazoles and isoxazoles. Eur J Med Chem, 2011; 46:5034-8.

Premakumari C, Muralikrishna A, Padmaja A, Padmavathi V, Park SJ, Kim T-J, Reddy GD. Synthesis, antimicrobial and anticancer activities of amido sulfonamido methane linked bis heterocycles. Arab J Chem, 2014; 7:385-95.

Ramaiah MJ, Pushpavalli SN, Krishna GR, Sarma P, Mukhopadhyay D, Kamal A, Bhadra U, Bhadra MP. Chalcone-imidazolone conjugates induce apoptosis through DNA damage pathway by affecting telomeres. Cancer Cell Int, 2011; 11:11.

Rapolu S, Alla M, Bommena VR, Murthy R, Jain N, Bommareddy VR, Bommineni MR. Synthesis and biological screening of 5-(alkyl (1H-indol-3-yl))-2-(substituted)-1,3,4-oxadiazoles as antiproliferative and anti-inflammatory agents. Eur J Med Chem, 2013; 66:91-100.

Spano V, Pennati M, Parrino B, Carbone A, Montalbano A, Lopergolo A, Zuco V, Cominetti D, Diana P, Cirrincione G, Zaffaroni N. [1,2]Oxazolo[5,4-e]isoindoles as promising tubulin polymerization inhibitors. Eur J Med Chem, 2016; 124:840-51.

Yin S, Tang C, Wang B, Zhang Y, Zhou L, Xue L, Zhang C. Design, synthesis and biological evaluation of novel EGFR/HER2 dual inhibitors bearing a oxazolo[4,5-g]quinazolin-2(1H)-one scaffold. Eur J Med Chem, 2016; 120:26-36.

Zhang L, Peng X-M, Damu GLV, Geng R-X, Zhou C-H Comprehensive review in current developments of imidazole-based medicinal chemistry. Med Res Rev, 2014; 34:340-437.

How to cite this article:

Abo-Elanwar YA, Mostafa AS, El-Sayed MAA, Nasr MNA. Synthesis and biological evaluation of new 2-(4-fluorophenyl) imidazol-5-ones as Anticancer Agents. J Appl Pharm Sci, 2019; 9(05):001-011. 